Sonnenholzner-Varas, J.I. (2021). ¿Hacia dónde va la acuicultura de equinodermos en América Latina? Potencial, retos y oportunidades. Revista de Biología Tropical, 69(S1), 514-549. DOI 10.15517/rbt. v69iSuppl.1.46393

\title{
¿Hacia dónde va la acuicultura de equinodermos en América Latina? Potencial, retos y oportunidades
}

\author{
Jorge I. Sonnenholzner-Varas ${ }^{1}$
}

1. Grupo de Investigación Biología y Cultivo de Equinodermos (INBICEQ), Departamento de Acuicultura y Pesquería, Facultad de Ciencias Veterinarias, Universidad Técnica de Manabí, Bahía de Caráquez, Manabí, Ecuador; jorge.sonnenholzner@utm.edu.ec

\author{
Recibido 31-VIII-2020. Corregido 12-XI-2020. Aceptado 09-XII-2020.
}

\begin{abstract}
Where is echinoderm aquaculture heading in Latin America? Potential, challenges and opportunities.

Introduction: Echinoderm aquaculture in Latin America is incipient, but it represents a new frontier for the highly nutritious marine food production, with native species of high commercial value offering a vast potential when compared to the weakened artisanal benthic fisheries. Methodology: We reviewed the literature on sea cucumbers, sea urchins, and starfish up to the year 2020. Results: By 2020, there were 17 native species with important advances in reproduction, larviculture, growth, treatment and identification of diseases, and nutrition, in Mexico, Belize, Panamá, Colombia, Ecuador, Peru, Brazil, Chile and Argentina. Conclusions: Echinoderm aquaculture in Latin America is advancing and would benefit from multitrophic systems to expand and diversify, reducing the pressure on depleted fisheries.
\end{abstract}

Key Words: sea cucumbers, sea urchins, starfish, integral multitrophic aquaculture.

El pan no está duro...duro es no tener pan.

(Pensamiento positivo de Wilder Hernández)

Vamos rumbo al 2022 y seguimos en la disyuntiva de aprovechamiento al máximo de los limitados recursos naturales y aumentar la producción de alimento de origen animal (FAO-FishStatJ, 2019ª; FAO-FishStatJ, 2019b) como fuente de provisión de proteína de alta calidad (cadenas largas de omega-3 con ácidos grasos altamente insaturados, HUFAs: EPA y DHA) y micronutrientes (tales como, hierro, zinc y selenio) para una creciente población mundial (Edwards, Zhang, Belton, \& Little, 2019; Boyd et al., 2020). Sin embargo, esto ocurre frente a desafiantes circunstancias generadas por la disminución de la productividad (en la magnitud de las capturas de especies costeras-marinas) por el síndrome de pesca excesiva, sobreexplotación y pesca ilegal, no declarada y no reglamentada - a pesar de estrictas medidas de ordenamiento y regulación pesquera, tales como, talla mínima de captura, cuotas, prohibición de captura, macro- y microzonificación de protección, concesiones otorgadas a cooperativas pesqueras, vedas, entre otras (Castrejón \& Bucaram, 2020). Sumado a esto, la contaminación de los ecosistemas, el cambio del patrón climático por la oscilación 
de los parámetros meteorológicos del Pacífico ecuatorial por El Niño-Oscilación del Sur (ENOS), el calentamiento y la acidificación oceánica global han cambiado la distribución y alterado la sincronía y capacidad reproductiva de algunas especies de interés comercial (Botsford, Castilla, \& Peterson, 1997; Thrush et al., 1998; Tegner \& Dayton, 2000; Watson \& Pauly, 2001; Chuenpagdee, Morgan, Maxwell, Norse, \& Pauly, 2003; Pyhälä et al., 2016; Cheng et al., 2019; Cheng, Abraham, Hausfather, \& Trenberth, 2019). Por su parte, la Organización de las Naciones Unidas para la Alimentación y la Agricultura (por sus siglas en inglés, FAO) ha determinado que la pesca y acuicultura son dos sectores estratégicos primarios de producción de alimentos a nivel mundial, pero la situación actual de ambos sectores es crítica por la inseguridad alimentaria y el estrés nutricional que han aumentado a un ritmo constante en la población mundial (FAO/ OMS, 2003; FAO, 2020a; FAO, 2020b). Desde 2014 la acuicultura es el sector con mayor crecimiento de producción global de alimento para consumo humano, pero este depende de pocos recursos, la mayoría no nativos (Troell et al., 2014) y la pesca de captura evidencia un marcado estancamiento en su producción sin signos de mejora, por efecto del ciclo auge y caída (Perry, Walters, \& Boutillier, 1999). En 2020, la producción acuícola mundial fue de 115 millones de ton, y 21 países latinoamericanos reportaron una creciente producción de cultivos marinos por sobre los de origen continental (Tabla 1). De estos, destacaron ocho países
(Chile, Brasil, Ecuador, México, Colombia, Perú, Honduras y Cuba) con una producción de 31 millones de ton (que representó el 74,3 \%) y en el intertanto, otros países empezaron a sumar producción (Wurmann, 2019).

Se han reportado 466 especies marinas susceptibles para la acuicultura y comercialización, incluyéndose varias especies ornamentales con interés para la creciente industria de la acuarofilia (se calculan ganancias sobre US\$ 300 millones con una tasa de crecimiento anual del $14 \%$, entre los que están muy bien representados los equinodermos, Livengood \& Chapman, 2007; Lango-Reynoso et al., 2012). Sin embargo, la FAO-Latinoamérica sólo reporta estadística de producción de dos grupos taxonómicos: (1) moluscos: $21 \%$ (correspondiente al chorito, Mytilus chilensis, ostión abanico, Argopecten purpuratus, los mejillones Perna perna - Brasil - Venezuela, y Mytella strigata - Brasil, Pectinidos, Argopecten purpuratus Perú - Chile, Nodipecten nodosus - México, y Nodipecten subnodosus - Brasil, ostras, Crassostrea gigas, C. virginica - México, y C. rhizophorae - Cuba) y (2) crustáceos: 53 $\%$ (sólo el camarón blanco, Penaeus vannamei - principalmente de Ecuador). El resto de los invertebrados $(26 \%)$ aparecen bajo el código “otras especies", incluyéndose a los equinodermos (FAO, 2020a).

El caso del cultivo del camarón blanco $P$. vannamei es resaltante, porque refiere a una industria multimillonaria de muy pocos países y una sola especie (inclusive, se espera que la producción en Ecuador alcance 700000

TABLA 1

Producción acuícola en América Latina y Caribe y a nivel mundial durante el periodo 2000-2017. Los valores son expresados en miles de toneladas. Fuente: Cálculos del estudio, sobre cifras FAO, FISHSTAT (2019) tomado de Wurmann (2019)

\begin{tabular}{cccccccc} 
Año & Caribe & A. Central & A. Sur & Marina & Continental & Total & Mundo \\
2000 & 40 & 89 & 710 & 568 & 271 & 839 & 13636 \\
2005 & 30 & 246 & 1233 & 1133 & 276 & 1509 & 18177 \\
2010 & 37 & 239 & 1579 & 1254 & 601 & 1855 & 21684 \\
2015 & 36 & 356 & 2269 & 1836 & 825 & 2661 & 26864 \\
2016 & 34 & 358 & 2316 & 1829 & 879 & 2708 & 26326 \\
2017 & 36 & 396 & 2511 & 2051 & 892 & 2943 & 30625 \\
Promedio & 36 & 281 & 1770 & 1445 & 641 & 2086 & 22885 \\
\hline
\end{tabular}


ton en 2021, siendo la tercera más grande del mundo, FAO, 2020b), cuyos stocks naturales están fuertemente disminuidos, similar a lo que ocurre a otros recursos bentónicos que se explotan, pero no se cultivan (Castilla \& Defeo, 2001; Agüero, 2007; Arreguín-Sánchez, 2009; Rueda, Rico-Mejía, \& Angulo-Vivero, 2011). De hecho, este sector ha sido afectado por la aparición y prevalencia de varias enfermedades en las granjas de cultivo de varios países, y por consecuencia, la caída del precio del camarón a nivel internacional. En tanto, la Revista Forbes Staff de febrero 2020, señaló la advertencia hecha por el Centro de Desarrollo de la Pesca y la Acuicultura del Ministerio de Agricultura y Ganadería del gobierno de El Salvador, que “(...) es eminente el colapso del monocultivo del camarón desde el sector industrial, artesanal y de algunos acuicultores, y propuso se exploren otras formas de cultivo, junto con búsqueda de financiamiento de sistemas adicionales a la reproducción de camarones como una medida permanente para crear impactos positivos a mediano y largo plazo". Cabe señalar que casi todos los programas gubernamentales y medidas aplicados a tal fin han virtualmente fracasado y ha agudizado la destrucción del hábitat de las especies que buscan ser cultivadas (Burchardt, 2017).

Por su parte, la FAO en 2015 impulsó la Agenda 2030 que incluyeron 17 Objetivos de Desarrollo Sostenible (ODS) y 169 metas, donde el ODS-14 implica: "Conservar y utilizar en forma sostenible (...) los recursos marinos para el desarrollo sostenible" para aumentar la producción acuícola y atender la crisis alimentaria, y al mismo tiempo reducir los impactos ambientales en toda la región, ya que se estima que unos 5.5 millones de ton de productos alimenticios acuícolas se requerirán para el 2030 (Wurmann, 2019). Pero, hoy en día la situación de la Pandemia Covid-19 (Boni et al., 2020) ha afectado severamente el desempeño económico de la entera región de América Latina y Caribe (CEPAL, 2020) registrándose un retroceso sin precedente en los últimos cien años (CELAC, 2020; FSIN, 2020), dificultándose la producción de alimentos (con enfoque a seguridad y soberanía alimentaria y sistemas alimenticios). Esto ha llevado a seguir debatiendo, aún más, sobre el dar paso al cultivo de nuevos recursos marinos nativos emergentes y la diversificación en acuicultura. En este contexto, se han generado lecciones que el sector acuícola habría de transformar en aprendizaje e innovaciones disruptivas y prospectivas (con visión a largo plazo) para el emprendimiento exitoso y sostenido de la diversificación que satisfaga el incremento en la demanda de productos para los próximos 30 años. Hoy, Latinoamérica busca incentivar el consumo de varias especies de equinodermos (Fig. 1, Fig. 2) por su enorme

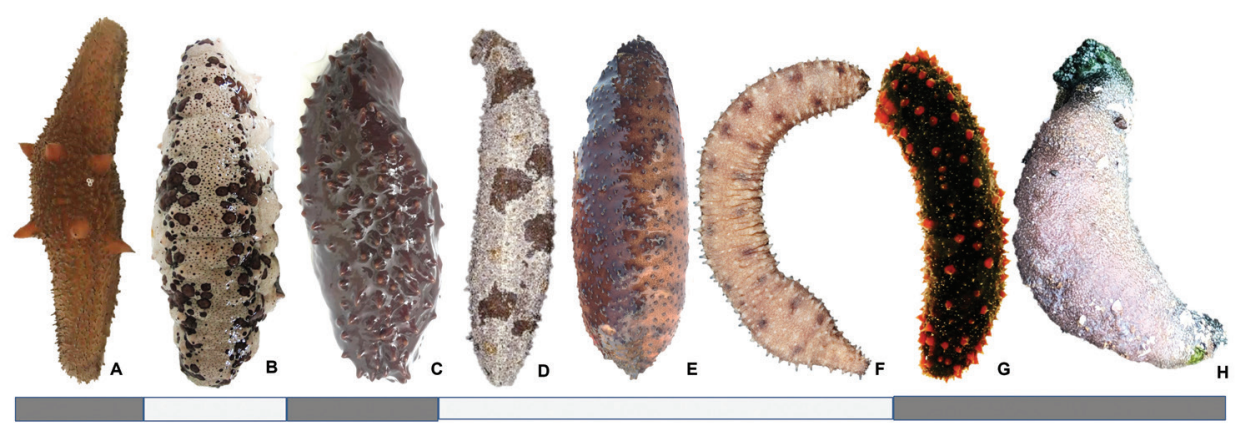

Océano Pacífico Este Océano Atlántico y Mar Caribe

Fig. 1. Especies nativas de pepinos de mar de interés comercial cultivadas en América Latina. A) Apostichopus parvimensis, B) Isotichopus badionotus; C) Isostichopus fuscus; D) Holothuria (Halodeima) floridana; E) Holothuria (Halodeima) grisea; F) Holothuria (Halodeima) mexicana; G) Holothuria (Selenkothuria) theeli; H) Athyonidium chilensis. 


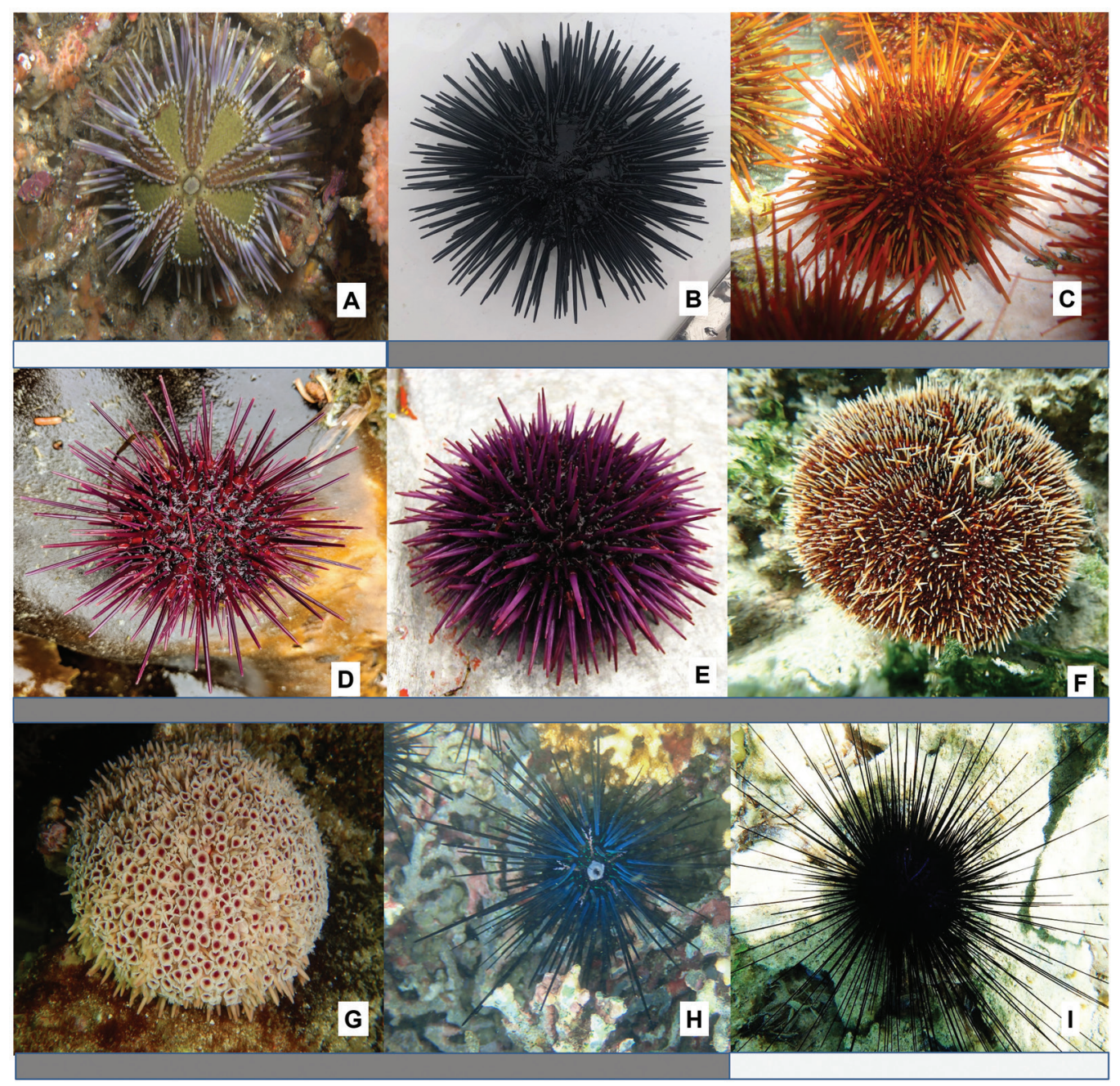

Océano Pacífico Este

Océano Atlántico y Mar Caribe

Fig. 2. Especies nativas de erizos de mar de interés comercial cultivadas en América Latina. A) Arbacia dufresnii; B) Arbacia stellata; C) Loxechinus albus; D) Mesocentrotus franciscanus; E) Strongylocentrotus purpuratus; F) Tripneustes depressus; G) Toxopneustes roseus; H) Diadema mexicanum; I) Diadema antillarum.

potencial comercial (considerados Manjares del Mar) siendo opciones alimenticias de calidad y nutritivas fuente de potentes moléculas bioactivas (García, Rosas, Rodríguez-Morales, 2013), y promover su cultivo en áreas adecuadas para la acuicultura, al reunir la mejor información científica en materia biológica, oceanográfica, climática y local, cuyas condiciones ambientales, integrando datos y conocimientos y presentándolos para discusión abierta que permitirá un proceso de decisión informado. Si bien somos una región bien dotada en biodiversidad, paradójicamente el consumo de productos del mar por habitante está entre los más bajos del mundo (Burchardt, 2017; FAO, 2020a) y esto va acompañado de 
la falta de inversión de capital por parte de los productores, retraso de contenido tecnológico disponible, y limitada producción científica que promuevan la diversificación. Es esencial que la acuicultura de equinodermos en América Latina vaya de la mano con un alto desempeño de producción de investigación científica aplicada. Según la base de datos Scopus $@$ y la revista científica El Profesional de la Información en el periodo 2014-2018, aumentó el número de instituciones con mayor capacidad consolidada de producción y actividad investigadora, destacando Brasil, México, Chile, Argentina y Colombia (que conformaron el grupo 1). En tanto, otros nueve países (del grupo 2) mejoraron su capacidad media de producción, siendo Ecuador el único país cuyas instituciones (con 6373 investigadores) publicaron más de 10 mil trabajos en varias áreas de conocimiento, entre ellas: Agricultural and Biological Sciencies con énfasis en la acuicultura. No obstante, los países del grupo 3 (que todavía son la mayoría, incluyen a América Central, Caribe, y parte de Sudamérica) continúan con muy baja producción científica (De Moya-Anegón et al., 2020; UNESCO, 2020). No obstante, hoy la paradoja es fortalecer a una industria alimentaria que utiliza muy pocas especies de cultivo que la mayoría son exóticas o introducidas, y que además no tienen estadística oficial de la FAO. Aparte de esto, persiste la problemática que queremos cultivar especies que están expuestas a pobre gestión pesquera, alta demanda del mercado y tráfico. Sin duda, todo esto tiene impacto en la biodiversidad aprovechable para el desarrollo de actividades productivas y obtención sostenible de alimento sano del mar (De Silva, 1989; Moyle \& Leidy, 1992; Cox, 1999; Naylor, Williams, \& Strong, 2001; De Silva, Nguyen, Turchini, Amarasinghe, \& Abery, 2009; Platas-Rosado \& VilaboaArroniz, 2014). El presente trabajo compila información reciente y muestra avances en el conocimiento aplicado sobre la acuicultura de varias especies de equinodermos con enfoque hacia la diversificación de la acuicultura marina de nuestra potente y biodiversa región latinoamericana. Es un bloque conformado de nueve países (de norte a sur, México, Belice, Panamá, Colombia, Ecuador, Perú, Brasil, Argentina y Chile) que presentan avances en aspectos clave del cultivo en reproducción, larvicultura, crecimiento, identificación y tratamiento de enfermedades y nutrición de 17 especies de equinodermos con enorme potencial económico (Fig. 1, Fig. 2) que destacan hacia el aprovechamiento en producción sostenible de alimentos y nutracéuticos por la facilidad de producción, demanda en el mercado y alto valor unitario (Sarmiento-Rubiano, 2006; Total-Granda, 2008; Sun \& Chiang, 2015).

\section{La acuicultura de equinodermos en América Latina}

Los equinodermos, más allá de ser animales carismáticos, icónicos y símbolo de la frágil vida marina asociada a ecosistemas saludables, no han pasado inadvertidos y trascienden desde lo ancestral hasta lo actual (Fig. 3, Fig. 4, Fig. 5, Fig. 6). Históricamente, civilizaciones antiguas (Egipto, Grecia, China y Roma) los consideraron animales únicos por su característica geométrica pentaradial que representaba lo sagrado, conexión en equilibrio con lo divino. Por ello, en la cultura milenaria China fueron dibujados en finas cerámicas en la dinastía Ming (siglos 13-17 A.C.) y en la cultura prehispánica de México y Perú fueron utilizados para actos ritualistas como ofrenda a deidades (Hooker, Prieto-Ríos, \& Solís-Marín, 2013; López-Luján et al., 2020). En la actualidad son ampliamente referidos no sólo como elementos iconográficos representativos del arte moderno, sino también por su relevancia en $(i)$ ciencia aplicada - los erizos de mar son un excelente registro fósil para estudios crono-paleoecológicos con enfoque al cambio climático y organismos modelo en biología del desarrollo con genoma completo secuenciado; (ii) industria de alimentos funcionales - los pepinos y erizos de mar son considerados Delicatesen, fuente de metabolitos secundarios (péptidos bioactivos, carbohidratos, ácidos grasos, colágeno, vitaminas y minerales) presentes en los músculos, vísceras, pared corporal, gónadas 

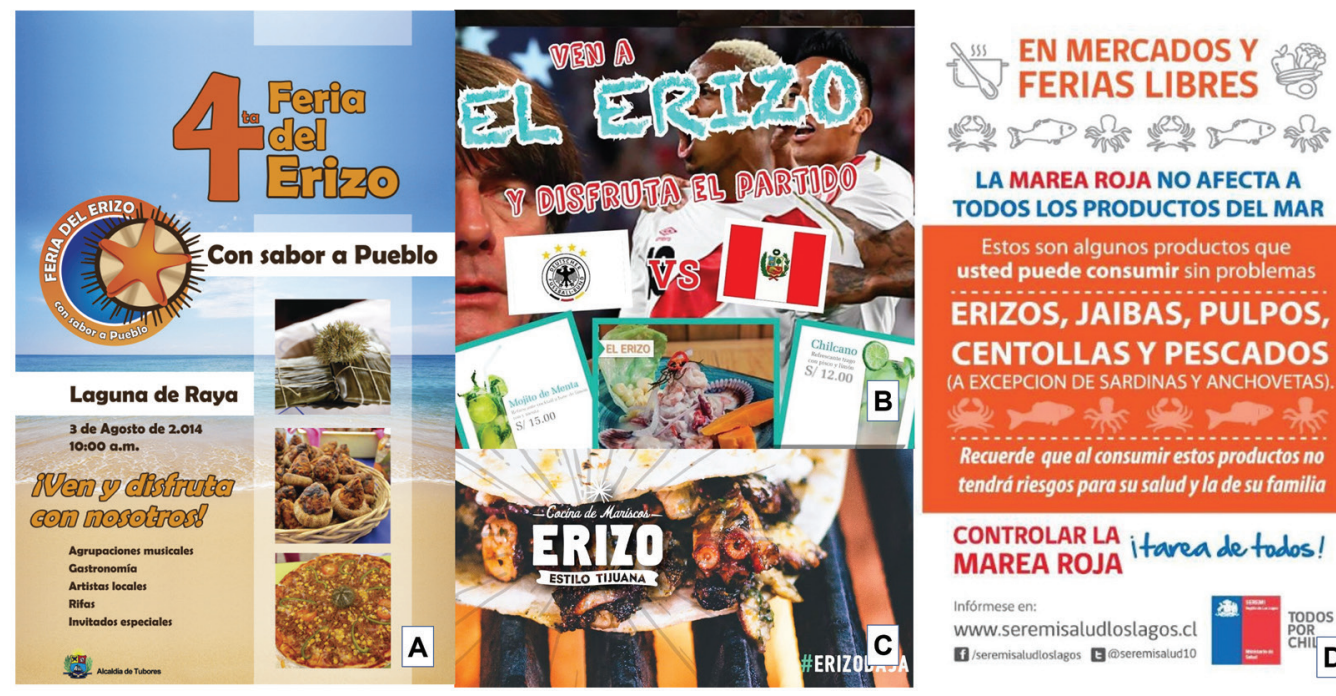

LA MAREA ROJA NO AFECTA A TODOS LOS PRODUCTOS DEL MAR

Estos son algunos productos que usted puede consumir $\sin$ problemas

ERIZOS, JAIBAS, PULPOS, CENTOLLAS Y PESCADOS (A EXCEPCION DE SARDINAS Y ANCHOVETAS).

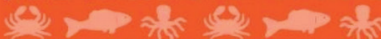
Recuerde que al consumir estos productos no tendrá riesgos para su salud y la de su familia CONTROLAR LA itarea de todos!
MAREA ROJA

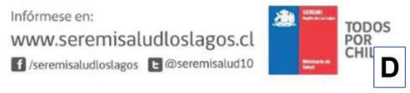

Fig. 3. Ruta gastronómica de equinodermos en América Latina. A) Feria del erizo de mar en la Isla Margarita, Venezuela; B) Piqueo de mariscos: erizo de mar en Lima, Perú; C) Comida Gourmet de erizo de mar en Tijuana, Baja California, México; D) Consumo de erizo de mar en mercados y ferias libres en la región sur de Chile.

y fluidos con efectos benéficos para la salud, como curación de heridas, neuroprotectores, antivirales, antitumorales, anticoagulantes, antimicrobianos, y antioxidantes, entre otros, y (iii) ecología funcional - conforman la biomasa de invertebrados más importante del fondo de todos los ambientes marino costeros del mundo que arma un complejo entramado en estructura y organización trófica béntico-pelágico (Bascompte \& Jordano, 2007; Gopal, Vijayakumaran, Venkatesan, \& Kathiroli, 2008; Micael, Alves, Costa \& Jones, 2009; De Zoysa, 2012; Kim y Himaya, 2013; Alves, Oliveira, Rosa, \& Cunningham, 2013). Pese a su importancia como recurso valioso para consumo humano, hoy las pesquerías de equinodermos son insostenibles (donde las capturas han sido dirigidas hacia todos los tamaños) y han puesto en riesgo y amenaza a muchas especies (Conand, 2004; Uthicke, 2004; Castrejón \& Charles, 2013). Frente a la marcada disminución de los stocks naturales de equinodermos alrededor del mundo, en los últimos años ha habido avance en el desarrollo y consolidación de la biotecnia de cultivo de pepinos y erizos de mar tropicales de rápido crecimiento, junto con la implantación de programas de legalización, regularización y acondicionamiento de laboratorios, y uso de granjas camaroneras abandonadas o subutilizadas de pequeños y medianos productores en Latinoamérica. Esto ha dado soporte a la estrategia de diversificar la acuicultura en el trópico para responder a la potencial demanda regional y del mercado asiático al 2030. No obstante, el rendimiento actual de la acuicultura de equinodermos sigue estando dominado por cultivos de pequeña escala dirigidos por pocos investigadores, dedicados principalmente al cultivo de pepinos y erizos de mar. Esto se traduce en una industria prácticamente incipiente con pesquerías disminuidas, principalmente de especies de latitudes templadas con lento crecimiento (Lawrence, 2007). De hecho, se concibe a la acuicultura de equinodermos como ciencia experimental recomendada para tratar de revertir la tendencia de sobreexplotación, mejorar el desempeño pesquero por un inadecuado manejo, y tener control sobre la producción sostenible de recursos, mediante programas de cultivo y repoblamiento a largo plazo (Berkes, Mahon, McConney, Pollnac, \& Pomeroy, 2001; Caddy \& Defeo, 2003; Ferdouse, 2004; Defeo, McClanahan, \& Castilla, 2007; McClanahan, 


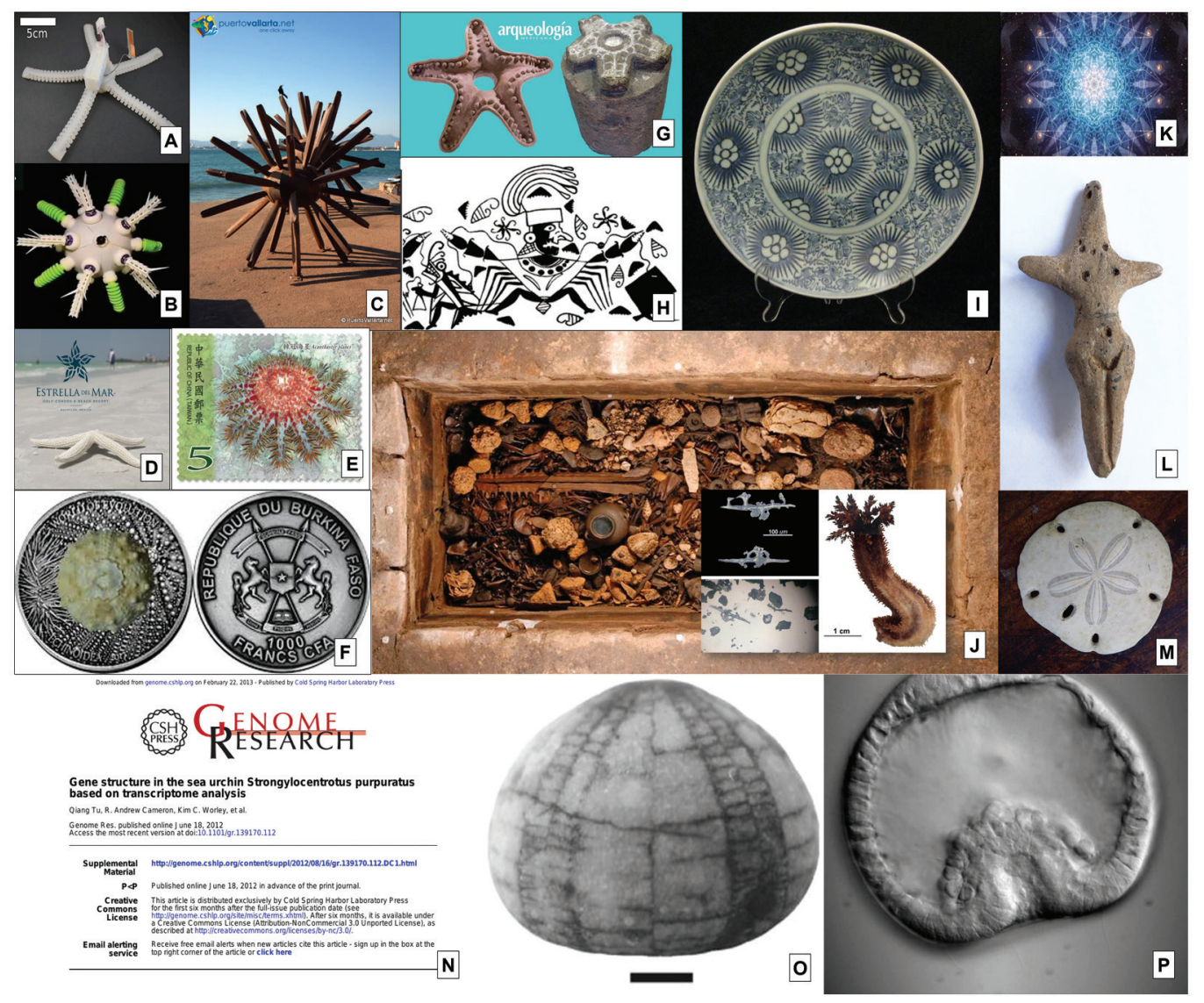

Fig. 4. Los equinodermos en el tiempo: en la ciencia A,B) Mini-robots autónomos; en la industria del turismo C-F) Esculturas de exhibición, folletería hotelera, estampillas y monedas de colección; G-L) Iconografía modelada prehispánica mexicana y del Perú (tomado de Hooker, Prieto-Ríos y Solís-Marín, 2013); Porcelana China fina de 1817, y rituales y entierros ceremoniales en la pirámide de Xochicalco, dedicada al culto a Tláloc, Arqueología Mexicana, M-P) investigación científica aplicada.

Castilla, White, \& Defeo, 2009; Defeo, Casti1la, \& Castrejón, 2009).

La producción mundial de equinodermos, específicamente de los erizos y pepinos de mar ocurre desde 1950 y 1970, respectivamente. En general, los datos de producción pesquera y acuícola de equinodermos (en capturas y cifras de desembarques) han sido generados por décadas con base en los informes publicados de las Estadísticas de Pesca de la FAO (FISHSTAT), pero se sabe que existen errores (en cifras confundidas y valores subestimados) que han hecho difícil realizar análisis directos en series de tiempo, y seguimiento con precisión de las capturas para cada recurso por país (Andrew et al., 2002; Sun \& Chiang, 2015; Slater, 2015). Por ello, se ha tenido que recurrir a datos de agencias de comercio internacional obtenidos de diferentes gobiernos, y agencias para verificación cruzada del conjunto de datos de Estadísticas de Pesca de la FAO (FISHSTAT) para más de 26 especies de equinodermos que se explotan en Latinoamérica para fines comerciales. De estas, más de 10 especies se capturan sólo en México (Tabla 1).

Son 850 especies de erizos de mar registradas a nivel mundial, y 17 especies son capturadas con interés comercial (Sun \& Chiang, 2015). 


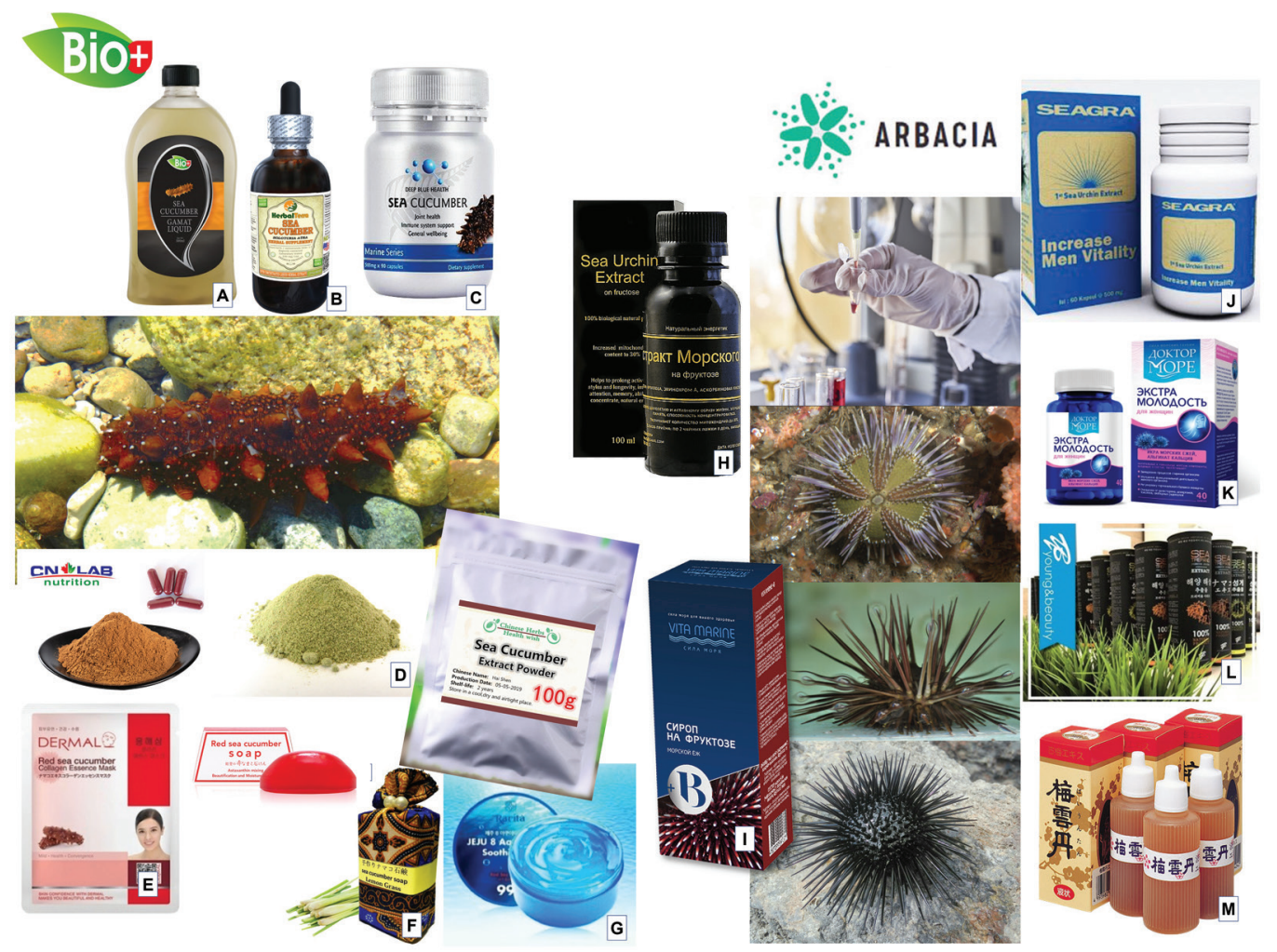

Fig. 5. Línea de productos nutracéuticos y cosmeacéuticos del pepino de mar Apostichopus japonicus (A-G) y su enorme potencialidad para los erizos de mar del genero Arbacia (H-M).

De estas, ocho son capturadas en pesquerías artesanales en Latinoamérica: Mesocentrotus franciscanus, Strongylocentortus purpuratus y Eucidaris tribuloides en México (SAGARPA, 2012, Lango-Reynoso et al., 2012), Echinometra lucunter, E. viridis, Lytechinus variegatus, Tripneustes ventricosus en Mexico, Venezuela y Cuba (Lango-Reynoso et al., 2012; del ValleGarcía, Abreu-Pérez, Solís-Marín, \& Laguarda-Figueras, 2013; Lodeiros, et al., 2013) y Loxechinus albus en Chile (Ayerbe et al., 2018). Las estimaciones a nivel global indican que el total de desembarques notificados entre 1961 y 1998 hubo un pico en 1995 de 120306 ton, y que disminuyó a 90257 ton en 1998. En 2012 el total de los desembarques descendió a 63291 ton. No obstante, esta tendencia fue diferente en Chile y México donde la producción incrementó. A finales de la década de
1980, Estados Unidos, Canadá, China, Corea del Norte y Corea del Sur fueron los principales países exportadores de erizo de mar a nivel mundial, pero desde 1990 Chile (con el erizo rojo $L$. albus) y México (con el erizo rojo $M$. franciscanus) representan más de la mitad de la producción mundial anual de erizos de mar. Sin embargo, sus cosechas disminuyeron para ambas especies (L. albus: un máximo de 60000 ton en 2001 a menos de 30000 ton en 2012 y M. franciscanus: un máximo de 8500 ton de peso vivo en 1986, a menos de 3000 ton en 2010). En tanto, la extracción del erizo morado mexicano (S. purpuratus) ha sido relativamente baja porque su gónada es considerada de menor calidad que la del erizo rojo $M$. franciscanus, por consiguiente es menos atractiva para el mercado. Por efecto, su población natural se ha incrementado en los últimos 20 años. Chile es 


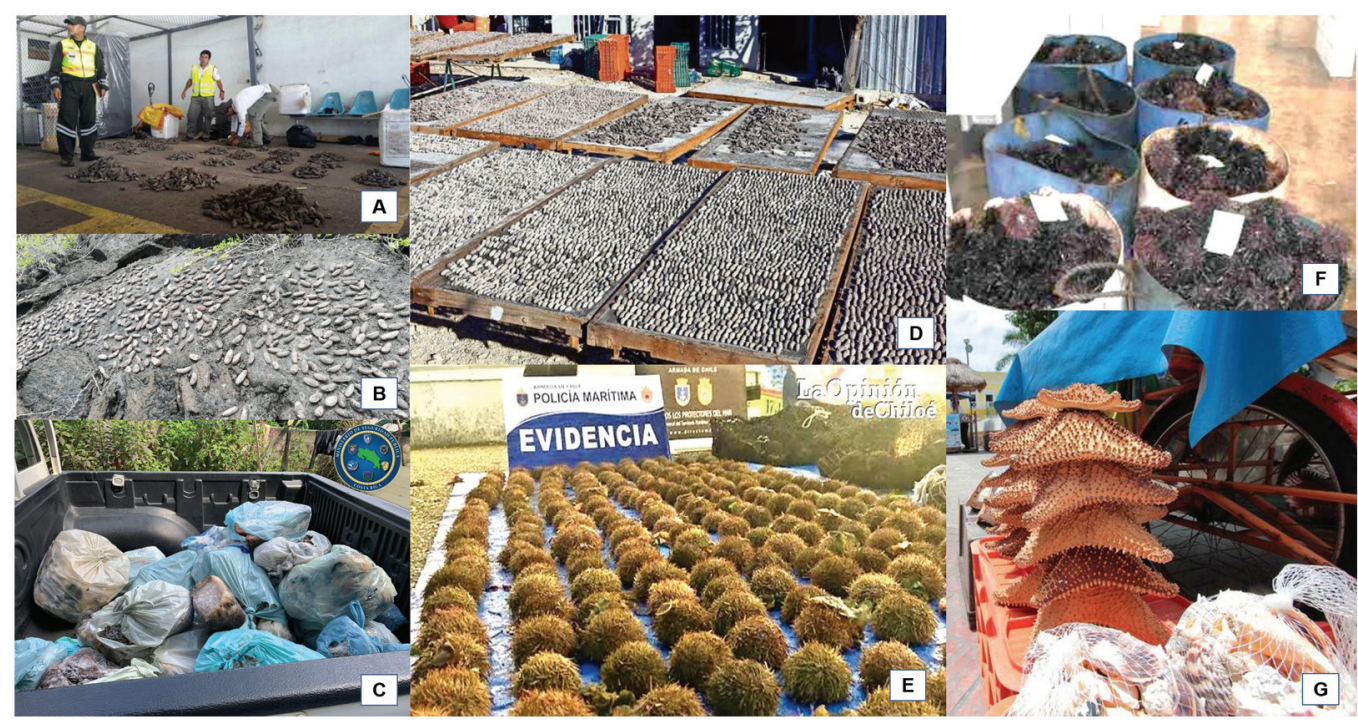

Fig. 6. Registro fotográfico del decomiso e incautación de equinodermos por pesca ilegal, publicadas por la prensa latinoamericana. A, B) pepino de mar procesado Isostichopus fuscus en Galápagos, Ecuador, Diarios El Comercio, 2016 y El Telégrafo, 2020; C) pepino de mar congelado I. fuscus en Guanacaste, Costa Rica, Guananoticias, 2020; D) pepino de mar procesado Isostichopus badionotus en Yucatán, México, La Universal, 2017; E) erizo de mar fresco Loxechinus albus en Chiloé, Chile, La Opinión de Chiloé, 2018; F) erizo de mar rojo fresco Mesocentrotus franciscanus en Ensenada, Baja California, México, Las Noticias del Océano, 2011; G) estrellas de mar secas en Cozumel, Quintana Roo, México, Novedades Quintana, 2016.

el único país de América Latina que ha emprendido varios programas de acuicultura a largo plazo para repoblamiento y recuperación de los stocks pesqueros del erizo de mar L. albus y aumentar su producción, pero no en México, ya que no existe acuicultura establecida de los erizos de mar M. franciscanus y S. purpuratus. Chile y México han sido los principales exportadores de erizo de mar congelado a Japón (país donde se consume más de 9000 ton de gónadas de erizo de mar cada año, equivalente a 70 g por persona cada año, Inui, 2008) y fresco a Estados Unidos (que conforman los dos mercados de erizo de mar más grande del mundo). En términos del mercado la calidad de las gónadas entre ambos erizos de mar es completamente distinta, y esto explica las fluctuaciones en el valor de las gónadas frescas de ambos erizos durante los últimos 25 años (de US\$ $10 \mathrm{~kg}^{-1}$ en 1988 a US\$ 20-25 kg-1 en 2018), ya que las gónadas del erizo chileno es de menor calidad que la de otros erizos de mar, incluyéndose la del erizo mexicano. Es por esta razón que estas gónadas son comúnmente comercializadas como producto congelado (e inclusive curado y/o aromatizado en salmuera) y/o mezcladas (chimni en la cocina japonesa) con otras gónadas para ser ofrecidas en restaurantes y mercados de precios moderados (Sun \& Chiang, 2015).

Son 1450 especies de pepinos de mar registradas a nivel mundial (Slater, 2015), pero las poblaciones naturales han drásticamente disminuido por pesquerías excesivas, y el número de pescadores "pepineros" ha ido en aumento con más de 3 millones de pescadores registrados alrededor del mundo (Purcell, Polidoro, Hamel, Gamboa, \& Mercier, 2014). La FAO identificó 58 especies comerciales tropicales y subtropicales pertenecientes a las familias de Holothuridae y Stichopodidae, incluidos los géneros Actinopyga, Bohadschia, Stichopus y Holothuria que son capturadas en más de 40 países (FAO, 2012). Sin embargo, en menos de seis años esta cifra se incrementó a más de 82 especies en más de 70 países (A. 
Lovatelli, com. pers. 2020). En 1990 la acuicultura de pepinos de mar estuvo referida a sólo dos especies comerciales, Apostichopus japonicus y Holothuria scabra con $45 \mathrm{mil} \mathrm{km}$ de línea de costa utilizadas para su cultivo, pero hoy son más de seis especies en 50 países con más de 609 mil km de línea de costa comprometidos para su acuicultura (A. Lovatelli, com. pers. 2020).

Por su parte, China, además de ser el principal consumidor e importador de pepinos de mar, también es el principal productor (Chen \& Chang, 2015; Katow, Okumura, Sakai, \& Shibuya, 2015; Tuwo \& Tresnati, 2015). En granjas acuícolas se han producido 200 millones ton al año (equivalente a casi US\$ 4 millones al 2010, cantidad que no es suficiente para abastecer la alta demanda del mercado, y por ello, han recurrido a la compra de pepinos de mar de otros países. Y más ahora que existen casos documentados como el reportado en agosto de 2018 por el periódico digital español El País que citó al diario China Daily, donde - "fuertes olas de calor (con picos máximos de temperatura de hasta $36{ }^{\circ} \mathrm{C}$ ) y el paso de varios tifones extremadamente fuertes golpearon el noreste de China que provocaron la muerte de millones de pepinos de mar (Fig. $7 \mathrm{~m}$ ) A. japonicus (equivalente a 68000 ton de animales) en una extensión de 63000 ha de granjas de cría situadas cercanas a la costa, con enormes pérdidas económicas para los productores en más de 870 millones de euros". Por ello, empresarios chinos, coreanos y japoneses (por efecto de la alta demanda del mercado asiático) emprendieron la búsqueda de nuevas especies de pepinos de mar y la conquista de nuevas áreas de pesca de fácil acceso y sin control en América Latina (países como, Costa Rica, Panamá, Colombia, Ecuador, Perú, Chile y Brasil), donde los habitantes locales no consumen el producto, no se conoce el estado natural de las poblaciones, e inclusive la pesquería está prohibida (Buitrago \& Boada 1996; Guzmán \& Guevara 2002; Choo, 2008; ToralGranda, 2008; Tagliafico, Salomé-Rangel, \& Rago, 2011). Según el informe de la FAO, en 2007, los datos de captura de pepinos de mar estuvieron disponibles para Ecuador, México, Chile y Nicaragua con una contribución total de 6035 ton (peso húmedo) para el período de 1988 hasta 2005 (van den Hoek, \& Bayoumi, 2017). En general, algunos países han llegado a exportar más de 20 especies, y en la actualidad pocas son las pesquerías que capturan una ( $I$. fuscus en Ecuador) o dos especies (Castilla \& Defeo, 2001; Orensanz et al., 2005). Por ejemplo, en Belice se han capturado varias especies como "muestras" para que los exportadores de pepinos de mar las envíen a Asia. Estas "muestras" incluyeron al pepino de mar Astichopus multifidus. Aunque la pesquería fue autorizada sólo para Isostichopus badionotus y Holothuria mexicana, varias otras especies fueron exportadas bajo el registro de " $H$. mexicana" o " $I$. badionotus" (A. Rogers, com. pers., 2020).

El pepino de mar I. fuscus es la especie de pepino de mar tropical de Latinoamérica mejor estudiada hasta ahora (Tabla 3), ya que es una de las preferidas del mercado y la tercera mejor cotizada del mundo: US\$ $1200 \mathrm{~kg}^{-1}$ (Purcell, Polidoro, Hamel, Gamboa, \& Mercier, 2014). El precio depende de la especie y su procedencia, tamaño y aspecto general del animal (Purcell, Ngaluafe, Lalavanua, \& Ceccarelli, 2018). En Galápagos, Ecuador se cerró la pesquería desde 2018 [indefinidamente] hasta que los stocks naturales se recuperen. Mientras que en la parte continental las poblaciones de I. fuscus están disminuidas desde que empezó la pesquería en 1993 y no se han recuperado por causa de la pesca ilegal y furtiva. La furtividad es conocida como efecto del fenómeno Transboundary Ilegal Fishing que ocurre entre varios países de la región que comparten el mismo recurso, por ejemplo: Ecuador-Perú (en isla Santa Clara - Ecuador). En tanto, las especies que actualmente se cultivan son principalmente del orden Synallactida: A. japonicus y otras siete especies para consumo como alimento de excelente calidad. Por ejemplo, A. japonicus es $85-95 \%$ de humedad, 3-6 \% proteínas, 2-4 $\%$, carbohidratos (0.2-0.4\%) y lípidos (0.2$0.4 \%$ ) (Saito, Kunisaki, Urano, \& Kimura, 2002). Las especies cultivadas para producción de ingredientes para cosmética y medicinas, 


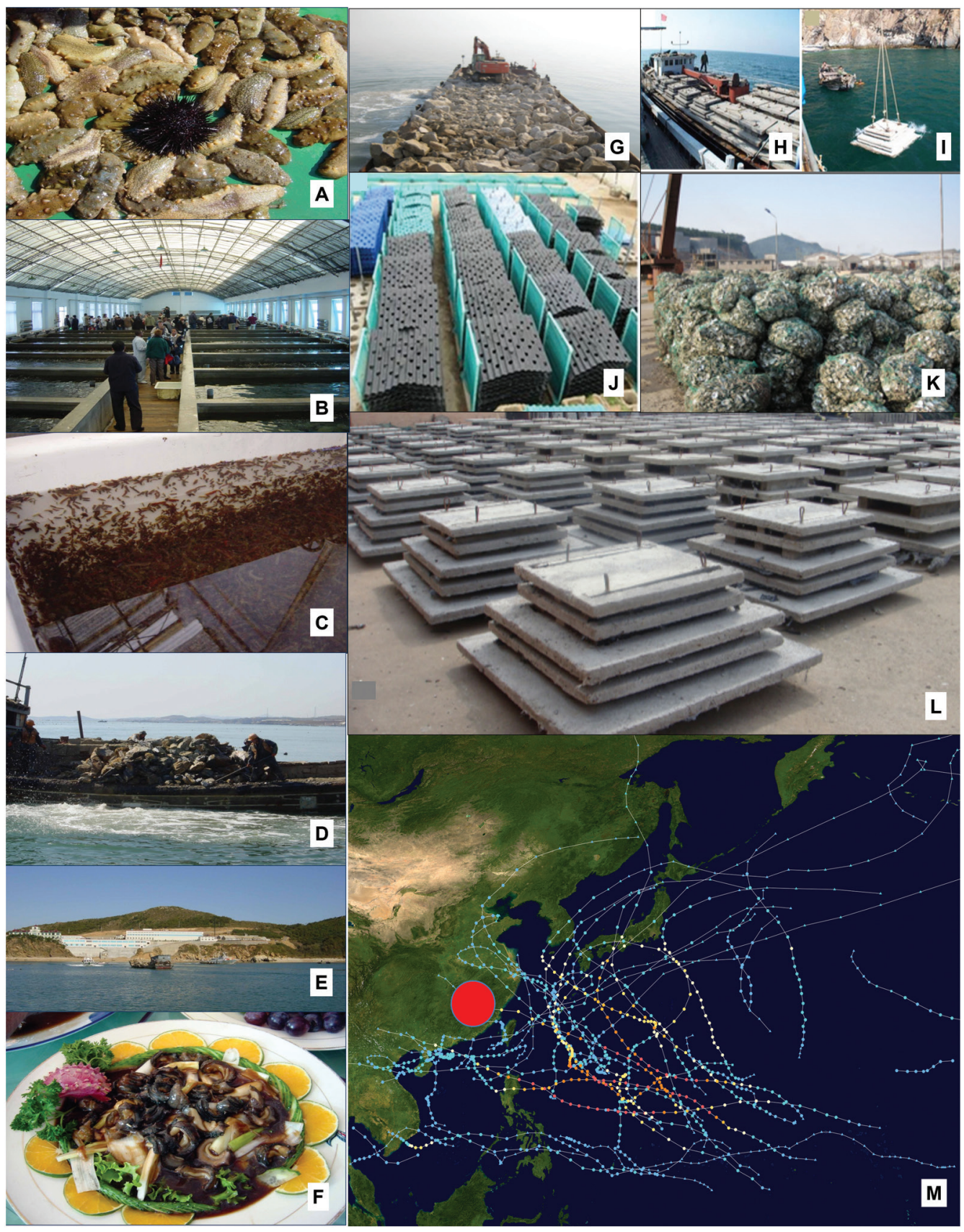

Fig. 7. Acuacultura del pepino de mar Apostichopus japonicus en China: A-C) Laboratorios de producción de semillas; D-L) infraestructura instalada en el borde costero tipo espigones y sumergidos tipo arrecifes que crean ambientes tridimensionales ideal para el cultivo masivo para consumo; M) Recorrido y trayectoria de varios súper tifones en el Océano Pacífico noroccidental que impactaron las costas de China durante el 2018. 
tenemos: Parastichopus nigripunctatus, Cucumaria japónica, Bohadschia argus, Stichopus chloronotus, Holothuria (Halodeima) atra, H. scabra y Thelenota ananas (Katow, Okumura, Sakai, \& Shibuya, 2015) en Japón; Stichopus japonicus (Zhou et al., 2006) y H. leucospilota (Yu, Hu, Zhou, Li, \& Peng, 2012) en China; $H$. scabra en India (James, Gandhi, Palaniswamy, \& Rodrigo, 1994), en Islas Salomón (Battaglene, Seymour, \& Ramofafia, 1999), en Vietnam (Pitt \& Nguyen, 2004), en Australia (Giraspy \& Ivy, 2005), y en Tailandia (Sithisak, Pongtippatee, \& Withyachumnarnkul, 2013), entre otros países; Australostichopus mollis en Nueva Zelandia; H. spinifera en India (Asha \& Muthiah, 2005) y Parastichopus californicus en Canadá (Paltzat, Pearce, Barnes, \& McKinley, 2008). Las especies que actualmente se cultivan en Latinoamérica son Isostichopus fuscus en Ecuador y México (Mercier, Ycaza, Espinoza, Arriaga-Haro, \& Hamel, 2014; Sonnenholzner, 2017; Sonnenholzner, Searcy-Bernal, \& Panchana, 2017); Isostichopus badionotus en México (Zacarías-Soto, Olvera-Novoa, Pensamiento-Villarauz, \& Sánchez-Tapia, 2013), en Belice (Rogers, 2018), Colombia (GómezLeón, López-Navarro, Benavides, Roa-Méndez, \& Santos-Acevedo, 2015), y en Bermuda (Sarkis, 2015); Holothuria floridana en Panamá (Luis Felaco, com. pers., 2020) y Holothuria mexicana en México y Belice (Rogers, 2018), H. theeli en Ecuador (Sonnenholzner, 2019; Sonnenholzner, Moreira, \& Panchana, 2019); Apostichopus parvimensis en México (Vela-Gallo, 2017), y Athyonidium chilensis en Chile (Guisado et al., 2012).

\section{PEPINOS DE MAR \\ Apostichopus parvimensis (Clark, 1913)}

Clasificación: Holothuroidea | Synallactida | Stichopodidae

Distribución: El pepino de mar A. parvimensis (Fig. 1a), comúnmente llamado en inglés "warty sea cucumber" es una especie que se distribuye desde Monterey Bay, E.U.A., hasta Baja California Sur, México (FajardoLeón, Suárez-Higuera, Valle-Manríquez, \& Hernández-López, 2008).

País que lo cultiva: México.

Gestión de producción: Al igual que otras especies comerciales de holoturias del Pacífico (Isostichopus fuscus) y Caribe mexicano (I. badionotus), A. parvimensis se encuentra en estado de vulnerabilidad por causa de la sobrepesca (Mercier et al., 2013). En 2015, investigadores mexicanos del laboratorio de producción de abulón de la Sociedad Cooperativa de Buzos y Pescadores Artesanales, Isla Natividad, Baja California Sur, documentaron el co-cultivo del pepino de mar A. parvimensis con el abulón verde Haliotis fulgens y registraron el desarrollo embrionario y larval completo del pepino de mar en condiciones controladas de laboratorio.

Avances al 2020: Los protocolos para desove y cultivo de larvas se encuentran completos. El pepino de mar $A$. parvimensis tiene un desarrollo larval que tarda 26 días en alcanzar la fase de asentamiento. La fase larval se divide en Auricularia temprana, media y tardía, presentándose al día 2,5 y 15 , respectivamente. Seguido por la fase de doliolaria media y tardía que se presentan al día 20 y 25 , respectivamente. A partir de aquí ocurre el asentamiento. Se requieren más estudios para completar el cultivo de juveniles (Bauer, 2016; Vela-Gallo, 2017).

\section{Isostichopus badionotus (Selenka, 1867)}

Clasificación: Holothuroidea | Synallactida| Stichopodidae

Distribución: El pepino de mar I. badionotus (Fig. 1b) está ampliamente distribuido en aguas poco profundas del Caribe (Guzmán, Guevara, \& Hernández, 2003) y desde el sureste de los Estados Unidos (Carolina del Norte) hasta el norte de Brasil hasta los $55 \mathrm{~m}$ de profundidad (Hendler, Miller, Pawson, \& Kier, 1995).

Países que lo cultivan: México, Belice, Panamá, Colombia. 
Gestión en producción: El colapso de la industria del camarón impulsó desarrollar capacidades técnicas colaborativas para diversificación de la actividad acuícola en la región, explorándose el potencial cultivo del pepino de mar I. badionotus en varios países. La demanda y precios altos que se pagan en el mercado asiático (US\$ $500 \mathrm{~kg}^{-1}$ procesado) aceleraron la disminución de las poblaciones naturales a lo largo de su rango de distribución del Atlántico y Mar Caribe. I. badionotus es considerada una especie de holoturia ideal para cultivos comerciales rentables (al igual que I. fuscus en el Pacífico) y coadyuvar a la recuperación de los stocks mediante la repoblación (Conand, 2001; Toral-Granda, 2008; Azari, Giraspy, \& Walsalam, 2010). Entre México, Colombia, Belice y Panamá se han ejecutado varias investigaciones con miras a la diversificación. Entre 2007 y 2010, la Unidad Mérida del Centro de Investigación y Estudios Avanzados del Instituto Politécnico Nacional (CINVESTAV-IPN) en Telchac Puerto, Yucatán, México, logró la condición de cautiverio para optimización de los protocolos de cultivo y producción de semillas de I. badionotus (Zacarías-Soto, Olvera-Novoa, Pensamiento-Villarauz, \& SánchezTapia, 2013), y entre 2011 y 2018, la empresa mexicana Acuacultura Dos Mil, S.A. de C.V., ubicada en las extensiones de Telchac Puerto, Yucatán y Champotón, Campeche, produjeron exitosamente juveniles de I. badionotus en cautiverio (DOF-SEGOP, 2015). Entre 2014 y 2015, el Programa colombiano de acuicultura sostenible (Convenio Especial de Cooperación PYR-VAR ITF) con la Universidad de Magdalena, el Instituto de Investigaciones Marinas y Costeras José Benito Vives de Andreis (INVEMAR) y la Gobernación del Magdalena, Santa Marta, financiaron el proyecto: "Importancia del recurso del pepino de mar Fase I: Evaluación del estado de las poblaciones naturales en el caribe colombiano y ensayos de cultivo en campo de I. badionotus especie de interés comercial". Se propuso el aprovechamiento sostenible y producción de juveniles, mediante captación de larvas del medio natural con colectores para cultivar pepinos de mar en cajas sumergidas en el mar (in situ) y la cría de pepinos de mar en laboratorio (GómezLeón, López-Navarro, Cerón Benavides, RoaMendéz, \& Santos-Acevedo, 2015). En 2015, Belice desarrolló capacidades técnicas colaborativas para explorar el potencial cultivo de I. badionotus en estanques de camaroneras. Y, entre 2016 y 2018, el Instituto de Investigación Ambiental de la Universidad de Belice (UB-ERI) con financiamiento de Bel-Euro Aquaculture Ltd., avanzó sobre el proyecto de acuicultura de I. badionotus en el sur de Belice. Intervinieron dos instituciones mexicanas, el Instituto Tecnológico de Lerma, Champotón y Aquacultura Dos Mil, S.A. de C.V., con avance en el desarrollo de estudios experimentales en colaboración con otros centros de maricultura en el Instituto Tecnológico de Lerma, Champotón, Campeche (Rogers, 2018). Entre 2017 y 2019 , investigadores mexicanos iniciaron estudios de acuicultura multitrófica, mediante el proyecto: "Bases biológicas y de manejo para la integración multitrófica del pepino de mar $I$. badionotus y macroalgas en sistemas de cultivo marino comercial de la corvina roja, Sciaenops ocellatus". Al 2020, la empresa panameña PANASEA tiene instalaciones de acuicultura comercial a gran escala en la costa caribeña de Panamá para producir y exportar pepinos de mar tropicales procesados, principalmente para los consumidores chinos a nivel mundial. Esta acción permitirá repoblar simultáneamente las poblaciones disminuidas, en el futuro sería un negocio sostenible, socialmente responsable y económicamente rentable.

Avances al 2020: La biotécnica para el desove y cultivo de larvas del pepino de mar I. badionotus se encuentra completa, pero se requiere diseñar y validar protocolos que permitan la reproducción plurianual de la especie. Se publicó un manual con información sobre la biología básica, reproductiva, desove, incubación y diversos aspectos de la tecnología de cultivo (Agudelo-Martínez, VergaraHernández, Villazón-Turizo, Pabón-Caro, \& Rodríguez-Forero, 2016). El cultivo de juveniles de I. badionotus ha sido experimental en condiciones de laboratorio y piloto comercial 
en estanques tierra adentro de 0.1 y 1 ha y en jaulas flotantes con una densidad de siembra de 3.2 individuos $/ \mathrm{m}^{2}$ (tiempo promedio preengorada: hasta 60 días y engorda: 14 meses) y en jaulas de 514 individuos $/ \mathrm{m}^{3}$ (tiempo promedio pre-engorda: 30 días y engorda: 12 meses), respectivamente. Hay avance de estudios en sistemas multitróficos para integración del cultivo de macroalgas, peces, manglar y salicornia con el pepino de mar I. badionotus, asimismo las densidades ideales y los requerimientos de sustrato específicos de los holotúridos.

\section{Isostichopus fuscus (Ludwig, 1875)}

Clasificación: Holothuroidea | Synallactida $\mid$ Stichopodidae

Distribución: El pepino de mar I. fuscus (Fig. 1c) está ampliamente distribuido en el Pacífico Oriental, desde el Golfo de California, México hasta el norte de Perú, incluyéndose las Islas Galápagos, Coco, Malpelo, Revillagigedo y Lobos de Afuera (Maluf, 1988).

Países que lo cultivan: México, Panamá, Ecuador, Perú.

Gestión en producción: El surgimiento de la enfermedad viral de la Mancha Blanca en 1999-2000 resultó en el cierre de varias granjas camaroneras afectando severamente a la industria acuícola latinoamericana (Rodríguez et al., 2003; Vázquez-Sauceda et al., 2016). Ante esta situación, Ecuador fue el primer país de la región que intentó el cultivo del pepino de mar I. fuscus. La empresa Investigaciones Especies Acuáticas, ubicada en la provincia de Santa Elena, desarrolló los estudios para producción de semillas. Los resultados se esbozan en Hamel, Ycaza, \& Mercier (2003), Mercier, Ycaza, \& Hamel (2004), y Becker, Eeckhaut, Ycaza, Mercier, \& Hamel (2009). Entre 2008 y 2011, la empresa mexicana Acuacultura Dos Mil S.A. de C.V., ubicada en Mazatlán, Sinaloa, consolidó la biotecnia de producción y engorda comercial de juveniles de I. fuscus en jaulas marinas y estanques de piscinas camaroneras (Fig. 8a-h). Los resultados fueron presentados por primera vez en 2012 (Mercier, Ycaza,
Espinoza, Arriaga-Haro, \& Hamel, 2012). En 2011, la empresa peruana Mar Picado E.I.R.L., ubicada en las costas de Playa Constante, en el distrito de Sechura, Piura, gestionó el permiso para desarrollar investigaciones y cultivo de $I$. fuscus (Resolución Directoral Regional N ${ }^{\circ} 746-$ 208-Gobierno Regional-Piura-DRP-DR) y el proceso de investigación avanza. Entre 2012 y 2017, se retomaron las investigaciones de I. fuscus en Ecuador, donde la Subsecretaría de Acuicultura del Ministerio de Agricultura, Ganadería, Acuicultura y Pesca, financió el proyecto: "Maricultura y piscicultura para el fomento acuícola en el Ecuador - pepino de mar Isostichopus fuscus" que se realizó en el Centro Nacional de Acuicultura e Investigaciones Marinas de la Escuela Superior Politécnica del Litoral (CENAIM - ESPOL), San Pedro de Manglaralto, Santa Elena. El proyecto fue reconocido y galardonado entre los mejores 500 proyectos de Latinoamerica para manejo y conservacion desde un enfoque de acuicultura y repoblación de especies vulnerables (Fig. 9a). En 2019, el Centro Reproductor de Especies Marinas del Instituto de Acuacultura de Sonora, México (CREMES-IAS) retomó el cultivo de I. fuscus para repoblamiento con fines comerciales. Por motivos de la pandemia el proyecto se detuvo y será retomado para el 2021 (C. Vela-Gallo, com. pers., 2020).

Avances al 2020: La biotecnología del cultivo por reproducción sexual y asexual (por fisión) del pepino de mar I. fuscus se encuentra completa (Hamel, Ycaza, \& Mercier, 2003; Mercier, Ycaza, \& Hamel, 2004; Becker, Eeckhaut, Ycaza, Mercier, \& Hamel, 2009; Sonnenholzner, 2017; Sonnenholzner,2019) y consolidada a nivel de producción de juveniles en jaulas marinas y estanques de piscinas camaroneras y liberación para repoblación. Ecuador elabora un manual de cultivo FAO de esta especie que incluye protocolos optimizados (Fig. 10a): sitios y selección de reproductores, manejo y acondicionamiento de reproductores, desove, fertilización, hatchery, cría de larvas, engorde, enfermedades y cuarentena, maduración de reproductores, y siembra-liberacion de juveniles para repoblamiento en áreas marinas 


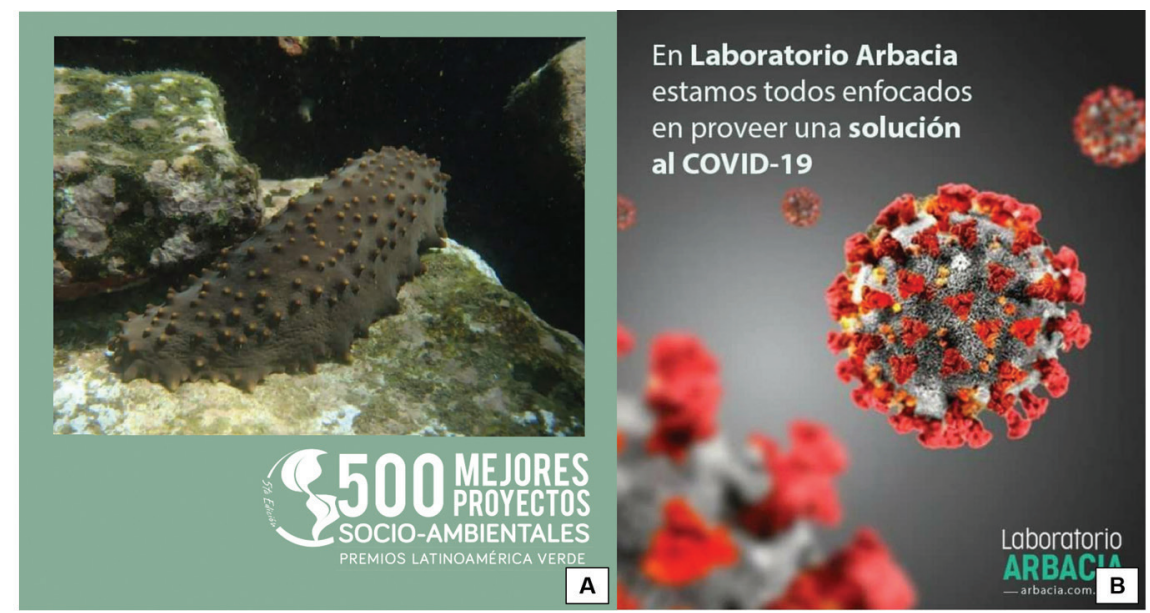

Fig. 8. Investigadores de la Red Iberoamericana de Equinodermos participaron en dos eventos de reconocimiento internacional: A) el proyecto titulado acuacultura y repoblación del pepino de mar Isostichopus fuscus en Ecuador fue galardonado entre los 500 mejores proyectos socio-ambientales en la 5ta. Edición Premios Latinoamérica Verde, Guayaquil - Ecuador, 2018, y B) el proyecto titulado biodescubrimiento de moléculas con propiedades antioxidante, antimicrobiano y antiviral del erizo de mar Arbacia dufresnii para fines terapéuticos del Covid-19, y la empresa ARBACIA de SRL fue varias veces galardonada, Patagonia - Argentina, 2020.

protegidas. El tiempo promedio del ciclo de cultivo y producción de semillas es 4 meses. El tamaño de los animales para la siembra es 3 $\mathrm{cm}$ de longitud total. La tasa de supervivencia es $90 \%$. Experimentos de cultivo de pepinos de mar en estanques de camaroneras demostraron que existe crecimiento en peso, que es una opción prometedora (Sonnenholzner, 2017).

\section{Holothuria (Halodeima) floridana (Pourtalés, 1851)}

Clasificación: Holothuroidea | Holothuriida| Holothuriidae

Distribución: El pepino de mar H. floridana (Fig. 1d) se encuentra ampliamente distribuido en zonas de pastos marinos en el Mar Caribe, el Gofo de México y la Florida hasta 5 $\mathrm{m}$ de profundidad (Pawson, Vance, Messing, Solís-Marín, \& Mah, 2009).

Países que lo cultivan: México, Belice, Panamá.

Gestión en producción: Entre 2010-2013, la Secretaría de Agricultura, Ganadería, Desarrollo Rural, Pesca y Alimentación (SAGARPA) por obtener información que le permita el manejo y administración para el aprovechamiento del recurso pepino de mar $H$. floridana. Se reunieron esfuerzos institucionales para desarrollar el proyecto "El pepino de mar de las costas de Campeche, potencialmente explotable (Ramos-Miranda et al., 2012). En 2014, mediante convenio varias instituciones mexicanas (Municipio de Champotón, Campeche - Tecnológico Nacional de México Instituto Tecnológico de Lerma - Secretaría de Pesca y Acuacultura - Coordinadora Nacional de las Fundaciones Produce A.C., INAPESCA) realizaron estudios de evaluación del crecimiento del pepino de mar $H$. floridana en sistemas de encierros rústicos sumergidos (DOF-SEGOP, 2015). En 2020, la empresa Acuícola del Mayab, Mérida, Yucatán, instalarían estructuras removibles tipo corrales en una granja en alta mar en Telchac Puerto (20 hectáreas del mar) para producir 98 toneladas de pepinos de mar por año (Proyecto Semarnat \#31YU2018PD145) para que sean localmente comercializados, a fin de coadyuvar la cadena de valor de este recurso en la Península de Yucatán. La empresa panameña PANASEA ubicadas en la costa del Caribe contempla 


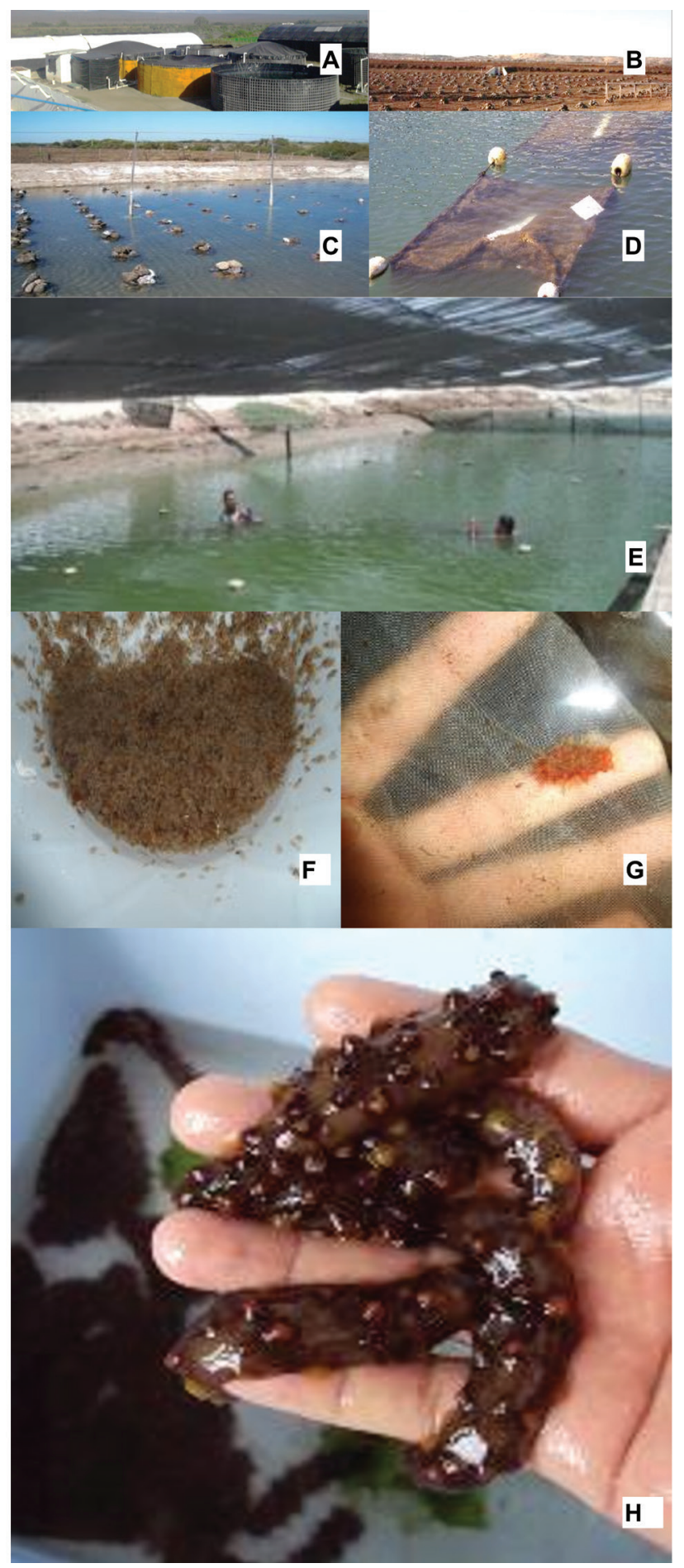

Fig. 9. Cultivo piloto del pepino de mar Isostichopus fuscus por la empresa Acuacultura Dos Mil SRL, en Sinaloa, México. A) Producción masivo de larvas hasta alcanzar etapa de pre-juvenil; B-E) Cultivo de juveniles en sistemas flotantes en piscinas camaroneras; F-H) Engorde de individuos. 

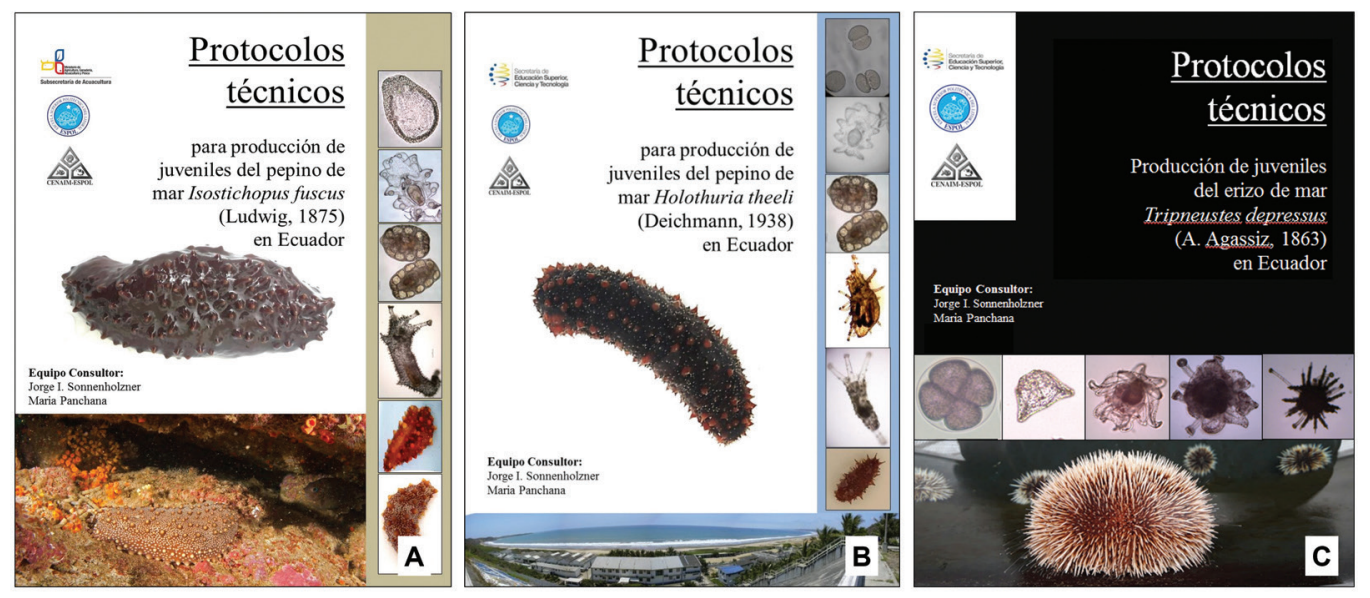

Fig. 10. Manuales de cultivo de tres proyectos de investigación para acuicultura de equinodermos, A) pepino de mar Isostichopus fuscus (2013-2017); B) pepino de mar Holothuria theeli (2015-2019); y C) erizo de mar Tripneustes depressus (2015-2019).

producir y exportar el pepino de mar $H$. florida$n a$. Esta acción permitirá repoblar simultáneamente las poblaciones disminuidas.

Avances al 2020: El estado actual de conocimiento sobre $H$. floridana, permite un adecuado manejo sustentable y administración del recurso en la acuicultura (Ramos-Miranda et al., 2012). Se registraron desoves naturales del pepino de mar $H$. floridana en condiciones de cautiverio en estanques durante los meses de julio-septiembre de 2017. Los juveniles pueden sobrevivir en distintos rangos de temperatura $\left(26-34{ }^{\circ} \mathrm{C}\right)$, oxígeno disuelto $\left(2-7 \mathrm{mg} \mathrm{l}^{-1}\right)$ y salinidad (20-32 ups). Dado que H. floridana presenta tolerancia a la manipulación y adaptación a los sistemas de confinamiento, se presenta como excelente opción para desarrollar su cultivo en el Golfo de México (RodríguezSerna, Carmona-Osalde, Guzmán-García, \& Puerto-Novelo, 2012).

\section{Holothuria (Halodeima) grisea (Selenka, 1867)}

Clasificación: Holothuroidea | Holothuriida| Holothuriidae

Distribución: El pepino de mar H. grisea (Fig. 1e) es una especie tropical ampliamente distribuida en las costas del este del continente americano y Caribe, desde la Florida, EUA, islas del Caribe, América Central, Brasil y al oeste de África (Caso, 1971; Pomory, 1989; Pawson, Vance, Messing, Solís-Marín, \& Mah, 2009).

País que lo cultiva: Brasil.

Gestión en producción: En Brasil se capturan principalmente dos especies de pepinos de mar, I. badionotus y H. grisea. H. grisea es la más abundante (Tommasi, 1969) y actualmente es reportada como fuente de consumo en Brasil (Hadel et al., 1999). Sin embargo, existe poca información disponible sobre el estado actual de las poblaciones del pepino de mar H. grisea a lo largo de la costa brasilera (Junior et al., 2017).

Avances al 2020: La acuicultura de $H$. grisea está en una fase inicial. Da Costa (2010) presentó una alternativa tecnológica para la acuicultura sustentable del pepino de mar $H$. grisea enfocado hacia el manejo de la carga de materia orgánica en policultivos de peces y ostras (Crassostrea gigas). Los mejores resultados en supervivencia y crecimiento fueron a densidades de 1,2 individuos por metro cuadrado en condiciones de $24{ }^{\circ} \mathrm{C}$ y 34 ups. 


\section{Holothuria (Halodeima) mexicana (Ludwig, 1875)}

Clasificación: Holothuroidea | Holothuriida| Holothuriidae

Distribución: El pepino de mar $H$. mexicana (Fig. 1f) se encuentra ampliamente distribuida en aguas poco profundas del Atlántico Occidental, desde el Golfo de México y el Mar Caribe, cubriendo Carolina del Sur, Bermuda, Florida, y parte de la península de Yucatán México, Venezuela, hasta el sur de Brasil, y también ha sido reportada en Azores (Pawson, Vance, Messing, Solís-Marín, \& Mah, 2009).

Países que lo cultivan: México, Belice, Panamá.

Gestión en producción: De las 49 especies de pepinos de mar reportados en América Central y Caribe, 21 se encuentran en Belice, siendo $H$. mexicana la más abundante (Rogers, Hamel, \& Mercier, 2018). Entre 2016 y 2018, Bel-Euro Aquaculture Limited, Distrito Toledo, sur de Belice, realizaron estudios para el cultivo del pepino de mar en estanques de camaroneras. Al 2020, la empresa panameña PANASEA tiene instalaciones de acuicultura comercial a gran escala en la costa para producir y exportar el pepino de mar H. mexicana. Esta acción permitirá repoblar simultáneamente las poblaciones disminuidas.

Avances al 2020: Reproductores de $H$. mexicana pueden aclimatarse en estanques de cultivo de camarones, pudiendo desovar naturalmente y criar juveniles en cautividad. Robledo \& Freile-Pelegrín (2011) mostraron el efecto biofiltrador efectivo del pepino de mar H. mexicana en sistema de efluentes de policultivos de camarones-peces. El cultivo de $H$. mexicana es viable en estanques, pero se requieren realizar más estudios.

\section{Holothuria (Selenkothuria) theeli (Deichmann, 1938)}

Clasificación: Holothuroidea | Holothuriida| Holothuriidae

Distribución: El pepino de mar $H$. theeli (Fig. 1g) está ampliamente distribuido en el
Pacífico Oriental, desde el Golfo de California, México hasta el norte de Perú, incluyéndose las Islas Galápagos, Coco, Malpelo, Revillagigedo y Lobos de Afuera (Maluf, 1988).

País que lo cultiva: Ecuador.

Gestión en producción: Con base en acuerdos ministeriales anteriores (No. 030, 031 y 042 del 28 de febrero y 8 de julio de 2013), el Viceministerio de Acuicultura y Pesca del Ecuador presentó el Acuerdo Ministerial No. 001, el 10 de enero de 2017 donde ratificó el desarrollo de proyectos de investigación para producción y repoblación de especies preferentemente nativas con enorme potencialidad para la acuicultura marina. En este contexto, la Secretaría de Educación Superior, Ciencia, Tecnología e Innovación (SENESCYT - Ecuador) financió el proyecto: "Desarrollo de protocolos de domesticación para el uso sostenible de nuevas especies marinas para consumo de alimentos y repoblación de bancos naturales - producción de semillas del pepino de mar Holothuria theeli (PIC-2014_CENAIM-002)" (Sonnenholzner 2019a). Entre 2015 y 2019 el proyecto se ejecutó en el Centro Nacional de Acuicultura e Investigaciones Marinas de la Escuela Superior Politécnica del Litoral (CENAIM - ESPOL), San Pedro de Manglaralto, Santa Elena.

Avances al 2020: La biotecnología del cultivo y producción del pepino de mar $H$. theeli se encuentra completa (Sonnenholzner, 2019a). El cultivo fue a nivel piloto experimental. El tiempo promedio del ciclo de cultivo y producción de semillas es 4 meses. El tamaño de los animales para la siembra es 3 $\mathrm{cm}$ de longitud total. La tasa de supervivencia fue del $90 \%$. Se elaboró un manual completo de cultivo del pepino de mar, que incluye: sitios y selección de reproductores, manejo y acondicionamiento de reproductores, desove, fertilización, hatchery, cría de larvas, engorde, enfermedades y cuarentena, y evaluación de métodos de marcaje para liberación de juveniles en el mar (Fig. 10b). Se promueve el cultivo de esta especie desde el enfoque de producción multitrófica utilizando las heces producidas del cultivo del erizo de mar Tripneustes depressus 
alimentados de algas marinas (Sonnenholzner, Moreira, \& Panchana, 2019).

\section{Athyonidium chilensis (Semper, 1868)}

Clasificación: Holothuroidea | Dendrochirotida| Cucumariidae

Distribución: El pepino de mar Athyonidium chilensis (Fig. 1h) está distribuido desde Perú hasta el sur de Chile (Maluf, 1988).

País que lo cultiva: Chile.

Gestión en producción: En Chile dos especies de pepinos de mar, Athyonidium chilensis (Semper, 1868) y Pattalus mollis (Selenka, 1868) son capturadas en las pesquerías desde 1990 (SERNAP, 2003), siendo, $A$. chilensis la más explotada (en 2015, US\$ 2500 $\mathrm{kg}^{-1}$ ), particularmente en el sur de Chile (SERNAP, 2008). Estudios previos han reportado aspectos relevantes de la biología básica y cultivo de A. chilensis (Fernández, 1998; Moreno, 2002; Pérez, 2005; González, 2006; Fernández, 2007; Maltrain, 2007; Guisado et al., 2012). Investigadores de la Universidad Valparaíso describieron las etapas tempranas del ciclo de vida del pepino de mar $A$. chilensis y sugirieron que la acuicultura de esta especie es factible y podría desarrollarse como una alternativa sostenible que eventualmente contribuiría a la restauración de los stocks naturales. Se busca desarrollar la acuicultura de esta especie y enseñarle a la población chilena a consumirlo.

Avances al 2020: La historia de vida temprana de $A$. chilensis no ha sido completamente descrita y todavía existe una brecha de conocimiento sobre la morfología, el desarrollo, el asentamiento y el crecimiento juvenil (Pérez, 2005; Guisado et al., 2012). A. chilensis es de lento crecimiento, se puede reproducir todo el año, produce larvas lecitotróficas (que se alimentan del vitelo del huevo) con dos periodos larvarios (larva vitelaria) y desde la fecundación son siete días para lograr larvas pentactula, y posterior juveniles. Para la etapa de pre-engorde, los juveniles presentan baja supervivencia, por lo que hay que mejorar la calidad de alimento y regular la temperatura óptima de cultivo. Estos dos factores son clave para lograr hacer un repoblamiento con individuos juveniles (35 días) de talla adecuada donde un alto porcentaje pueda sobrevivir (1.2 mm de longitud, 4 meses de cultivo).

\section{ERIZOS DE MAR}

\section{Arbacia dufresnii (Blainville, 1825)}

\section{Clasificación: Echinoidea | Arbacioida | Arbaciidae}

Distribución: El erizo de mar $A$. dufresnii (Fig. 2a) se encuentra distribuido en el Pacífico desde Puerto Montt al sur y hasta el Rio de la Plata por el Atlántico, hasta los $315 \mathrm{~m}$ de profundidad (Maluf, 1988).

País que lo cultiva: Argentina.

Gestión en producción: En la Patagonia de Argentina, hace más de una década el Centro para el Estudio de Sistemas Marinos (CESIMAR), en el Centro Nacional Patagónico (CENPAT) estudian al erizo de mar verde $A$. dufresnii. Con base en estas investigaciones, el Instituto de Micología y Botánica (INMIBO) de la Facultad de Ciencias Exactas y Naturales de la Universidad de Buenos Aires, encontraron un potencial en la extracción de metabolitos secundarios del erizo A. dufresnii. Estos compuestos orgánicos que son sintetizados por los organismos vivos son muy cotizados en industrias como la farmacéutica, la cosmética y la de alimentos balanceados de alta calidad. Donde, los metabolitos secundarios pueden servir para evitar los efectos secundarios no deseados de medicamentos, entre otras aplicaciones. Es por ello que se decidió instalar un criadero de $A$. dufresnii que permitiría comercializar productos biotecnológicos, desde un manejo adecuado y ético para la especie. Tras este hallazgo, se creó el Startup ARBACIA (primera iniciativa en el mundo dedicada al cultivo de erizos de mar con fines biotecnológicos en lugar de gastronómicos). Esta innovación le valió el premio de mejor emprendimiento de Latinoamérica en 2019 - erizos que servirían como fármaco para combatir el Covid-19 (Fig. 9b). Por sus características, el erizo tiene un potencial no solo para 
la cocina Gourmet, sino nutracéutico. La iniciativa surgió de una articulación público-privada promovida por el Gobierno de Chubut entre investigadores del CONICET y actores privados. La planta industrial está en la fase final de su construcción y finalizará la obra a mediados del 2020. Estará ubicada en Puerto Madryn, Chubut - Argentina y cuenta con diferentes áreas: (i) laboratorio de producción de alimento, (ii) larvicultura, (iii) engorde de juveniles, y (iv) manejo de adultos reproductores.

Avances al 2020: El erizo de mar $A$. dufresnii no había sido estudiada desde los años $80 \mathrm{~s}$. Se han realizado varios estudios in vitro utilizando química computacional, $\mathrm{y}$ protocolos validados a nivel internacional para medir el efecto del 1,4-naftoquinona polihidroxilasa (Echinocromo A), en el coronavirus SARS-CoV-2 (Rubilar et al., 2020; Barbieri et al., 2020).

\section{Arbacia stellata (Blainville, 1823)}

\section{Clasificación: Echinoidea | Arbacioida Arbaciidae \\ Distribución: El erizo de mar A. stellata} (Fig. 2b) está presente en la costa este del Pacífico, distribuido desde las cosas de Baja California, México hasta Perú (Maluf, 1988).

Países que lo cultivan: México, Ecuador

Gestión en producción: Investigadores ecuatorianos de la Facultad de Acuicultura de la Universidad Técnica de Manabí, Bahía de Caráquez, Manabí, ejecutan el proyecto: "Desarrollo de protocolos de producción de juveniles y de caracterización de sustancias nutracéuticos del erizo de mar Arbacia stellata (Blainville, 1823) para diversificación acuícola en Manabí, Ecuador". Se promueve el cultivo de $A$. stellata con visión hacia la diversificación de la matriz productiva acuícola y nutracéutica en Ecuador, mediante la detección de moléculas presentes en los pigmentos del fluido celómico de machos y hembras y en las gónadas de hembras con potentes propiedades químicas antioxidante y antiinflamatorias que podrían servir para tratamiento antiviral del Covid-19. De este modo, se busca incrementar los metabolitos secundarios antioxidantes (pigmentos carotenoides y ácidos grados) de interés comercial, por medio del incremento de la calidad del alimento formulado y balanceado en dietas. Por otra parte, investigadores mexicanos del Laboratorio de Ecología y Biología del Desarrollo (ECODEL) del Instituto de Investigaciones Oceanológicas de la Universidad Autónoma de Baja California, y de la Universidad del Mar, Puerto Angel, Oaxaca, realizaron estudios sobre los estadios tempranos de vida de $A$. stellata y su amplificación en distribución en aguas del Pacífico (Díaz-Martínez, 2019).

Avances al 2020: De las seis especies descritas del género Arbacia, en Ecuador están presentes dos, Arbacia spatuligera y A. stellata (antes $A$. incisa). Es necesario más información de las poblaciones de $A$. stellata a lo largo de su rango de distribución en la costa este del Pacífico, porque esta especie de erizo posee características y atributos biológicos (rápido crecimiento con producción de gónadas grandes) que la hacen atractiva para la acuicultura multitrófica en sistemas de cultivo flotante de ostras (Sonnenholzner, Alcívar, Márquez, \& Lodeiros, 2017) por su potencial uso nutracéutico y farmacéutico (Sucklinga, Kelly, \& Symonds, 2020).

\section{Loxechinus albus (Molina, 1872)}

\section{Clasificación: Echinoidea | Camarodonta| Parechinidae}

Distribución: El erizo de mar rojo $L$. albus (Fig. 2c) se distribuye desde la Isla Lobos Afuera, Perú hasta Cabo de Hornos, Chile. $\mathrm{Su}$ dispersión oriental llega hasta la Isla de los Estados y se distribuye batimétricamente, desde la zona intermareal hasta $340 \mathrm{~m}$ de profundidad (Castilla, 1990).

Países que lo cultivan: Perú, Chile.

Esfuerzos de gestión: La pesquería de L. albus ocurre en Chile y Perú desde 1970 y los stocks están fuertemente disminuidos (Vásquez, 2020). Por ello, se ha buscado refuerzo de la acuicultura para mejorar los stocks mediante la repoblación. En el marco del 
proyecto FONDEF - Chile: "Diversificación de la acuicultura en la X Región” priorizó la producción de semillas y engorde de esta especie de erizo en el mar, junto con la elaboración de manuales de cultivo del erizo rojo L. albus (Yamashiro, Benites, Zeballos, \& Tafur, 1996; Ayerbe et al., 2018). En 2015, el Laboratorio Costero de Ilo, Perú, desarrolló el proyecto: "Producción de juveniles del erizo Loxechinus albus (Molina, 1782) en medio controlado y experimentalmente en sistemas de cultivo suspendido en medio natural en la zona sur del Perú" para obtener juveniles en laboratorio, y posterior engorde en el mar. En 2019, investigadores de la Facultad de Ciencias de la Vida, Universidad Andrés Bello - Chile, presentaron el proyecto: "Innovación social y tecnológica para impulsar la acuicultura a pequeña escala (BIP30480912-0)". Este proyecto innovador promueve la transferencia tecnológica del cultivo de semillas del erizo rojo a los pescadores artesanales de caletas pesqueras de la Región de Valparaíso. El proyecto se desarrolló en el Centro de investigación Marina de Quintay (CIMARQ) y fue financiado con aportes del Gobierno Regional de Valparaíso. Se generó un Manual para la producción de semillas de erizo rojo (Silva, 2019).

Avances de cultivo: Ayerbe et al. (2018) refirieron sobre la biotecnología de cultivo del erizo rojo en ambientes controlados y a nivel experimental en sistemas suspendidos en la zona sur del Perú. El cultivo inicial comprende dos etapas, la embrionaria de 48 horas y la larvaria (prisma, 4 brazos, 6 brazos y 8 brazos) de 25 días en condiciones controladas de temperatura, aireación, agua estéril. La etapa poslarvaria (cultivo intermedio) abarca un período de 37 días de desarrollo donde ocurre el asentamiento en superficies colonizadas con diatomeas (Zamora \& Stotz, 1994) hasta alcanzar 1 $\mathrm{mm}$ de diámetro y se desarrolla en condiciones semicontroladas (agua de mar filtrada hasta 75 $\mu \mathrm{m})$. Finalmente, los juveniles son trasladados a un sistema de cultivo suspendido en medio natural donde se inicia la etapa de engorde. Es de crecimiento lento (promedio: 0.1 a $0.3 \mathrm{~cm}$ $\mathrm{mes}^{-1}$ ). Las épocas de desove del erizo rojo entre Perú y Chile se atribuyen a la variación latitudinal de la temperatura (Reyes et al., 1991; Arias, Barahona, Lozada, \& Jerez, 1994).

\section{Mesocentrotus franciscanus (A. Agassiz, 1863) \\ y Strongylocentrotus purpuratus (Stimpson, 1857)}

Clasificación: Echinoidea | Camarodonta| Strongylocentrotidae

Distribución: El erizo rojo, $M$. franciscanus (Fig. 2d) y el erizo morado, S. purpuratus (Fig. 2e), se distribuyen geográficamente desde Alaska hasta Isla Natividad, Baja California Sur (Maluf, 1988). Ambas especies habitan en la zona submareal con fondos rocosos, comúnmente asociados a la comunidad de los mantos de algas marinas Macrocystis pyrifera, entre los 3 y 50 metros de profundidad. En México, específicamente se le localizan en la costa occidental de la Península de Baja California desde las Islas Coronado hasta Isla Cedros, Baja California e Isla Natividad, Baja California Sur, México.

País que los cultivan: México.

Gestión en producción: La acuacultura marina es una actividad productiva prioritaria en México, desde el enfoque de su diversidad biológica (Solís-Marín et al., 2013), pero su desarrollo continua siendo incipiente y demanda mayor impulso. Entre 2007 y 2012, el Plan Nacional de Desarrollo y del Programa Sectorial de Desarrollo Agropecuario y Pesquero, junto con el Instituto Nacional de Pesca (INAPESCA), propusieron estrategias de manejo con enfoque precautorio que asegure la sustentabilidad de las pesquerías de $M$. franciscanus y $S$. purpuratus, mediante la acuacultura. Investigadores del Departamento de Acuicultura del Centro de Investigación Científica y de Educación Superior de Ensenada, Baja California y del Instituto de Investigaciones Oceanológicas de la Universidad Autónoma de Baja California, ambas instituciones académicas y de investigación promueven la acuicultura de ambas especies de erizos con fines de investigaciones aplicadas para la acuicultura. 
Avances al 2020: Acuicultura de ambas especies de erizos de mar para la comercialización de gónadas no existe, pero hoy se cuenta con información suficiente sobre la biología y ecología fundamental de ambas especies para empezar formalmente su cultivo. No obstante, es necesario realizar estudios que evalúen los efectos de las dietas formuladas sobre el crecimiento y la calidad nutricional de las gónadas de ambas especies. Por ello, el estudio de Cuesta-Gómez, Lazo, \& Sánchez-Saavedra (2020) allana el camino para futuras investigaciones en nutrición del erizo morado y rojo.

\section{Tripneustes depressus (Agassiz, 1869)}

\section{Clasificación: Echinoidea | Camarodonta Toxopneustidae}

Distribución: El erizo de mar T. depressus (Fig. 2f) está ampliamente distribuido en el Pacífico Oriental, desde el Golfo de California, México hasta el norte de Perú, incluyéndose las Islas Galápagos, Coco, Malpelo, Revillagigedo y Lobos de Afuera (Maluf, 1988).

País que lo cultiva: Ecuador.

Gestión en producción: Al igual que con el pepino de mar $H$. theeli, la Secretaría de Educación Superior, Ciencia, Tecnología e Innovación (SENESCYT - Ecuador) financió el proyecto: "Desarrollo de protocolos de domesticación para el uso sostenible de nuevas especies marinas para consumo de alimentos y repoblación de bancos naturales - producción de semillas del erizo de mar Tripneustes depressus (PIC-2014_CENAIM-002)" (Sonnenholzner, 2019b). Entre 2015 y 2019, el estudio se realizó en el Centro Nacional de Acuicultura e Investigaciones Marinas de la Escuela Superior Politécnica del Litoral (CENAIM - ESPOL), San Pedro de Manglaralto, Santa Elena. En 2015, la Escuela de Gastronomía de la Asociación de Chef de Santa Elena, Ecuador identificaron a esta especie de erizo de mar como una especie potencial para cultivo y consumo por la calidad de sus gónadas, durante el evento: "Valoración de potenciales nuevos recursos marinos como registro de marca gastronómica en Ecuador".

Avances al 2020: La biotecnología del cultivo y producción del erizo de mar $T$. depressus se encuentra completa (Fig. 10c). Los cultivos se realizaron a nivel experimental (Sonnenholzner, Touron, \& Panchana-Orrala, 2018; Sonnenholzner, 2019b). El tiempo promedio del ciclo de cultivo y producción de semillas es 4 meses. La tasa de supervivencia fue del $90 \%$. Se elaboró un manual completo de cultivo del erizo de mar $T$. depressus, que incluye: sitios y selección de reproductores, manejo y acondicionamiento de reproductores, desove, fertilización, hatchery, cría de larvas, engorde, enfermedades y cuarentena, y evaluación de métodos de marcaje para liberación de juveniles en el mar. Se promueve el cultivo de esta especie desde el enfoque de producción multitrófica utilizando algas marinas producidas en cultivo (por ejemplo, Kappaphycus alvarezii) para producción de heces que pueden ser utilizadas para alimentar pepinos de mar (Sonnenholzner, Moreira, \& Panchana, 2019). La maduración de adultos y el crecimiento de sub-adultos T. depressus en cautiverio se logró mediante dietas preparadas que promuevan el crecimiento y la maduración gonadal (Sonnenholzner, 2019b).

\section{Toxopneustes roseus}

(A. Agassiz, 1863)

\author{
Clasificación: Echinoidea | Camarodonta| \\ Toxopneustidae
}

Distribución: El erizo de mar $T$. roseus (Fig. 2g) es la única especie reportada en la costa Este del Pacífico. Puede encontrarse desde península de Baja California, México hasta el norte del Perú y en aguas de las islas Galápagos. Común en zonas de arrecifes rocosos asociados a coral, entre 2 y $50 \mathrm{~m}$ de profundidad (Maluf, 1988).

País que lo cultiva: Ecuador.

Gestión en producción: No existe una pesquería dirigida hacia esta especie de erizo. 
Avances al 2020: La acuicultura de $T$. roseus está en fase experimental (J. Sonnenholzner, com. pers. 2020).

\section{Diadema mexicanum}

\section{(A. Agassiz, 1863)}

Clasificación: Echinoidea | Diadematoida| Diadematidae

Distribución: El erizo de mar D. mexicanum (Fig. 2h) es una especie tropical ampliamente distribuida en la costa Este del Pacífico, desde la península de Baja California, México hasta el norte del Perú (Maluf, 1988).

País que lo cultiva: Ecuador.

Gestión en producción: En México, $D$. mexicanum es capturado para comercio ornamental y uso en acuarios (Piña-Espallargas, 2004), pero se ha sugerido establecer una pesquería sobre esta especie para consumo humano por la calidad y tamaño de sus gónadas (Alvarado, Cortés, \& Reyes-Bonilla, 2012). Es una especie de rápido crecimiento $\mathrm{y}$ ha sido considerada candidata para la acuicultura (Muthiga \& McClanahan, 2013; Sonnenholzner, Touron, \& Panchana-Orrala, 2018). En 2015, la Escuela de Gastronomía de la Asociación de Chef de Santa Elena, Ecuador identificaron a esta especie de erizo de mar como una especie potencial para cultivo y consumo por la calidad de sus gónadas, durante el evento: "Valoración de potenciales nuevos recursos marinos como registro de marca gastronómica en Ecuador".

Avances al 2020: En Ecuador, la acuicultura de $D$. mexicanum se encuentra en fase experimental (J. Sonnenholzner, com. pers. 2020). Existen muy pocos estudios de la biología reproductiva de $D$. mexicanum (BenítezVillalobos, Ávila-Poveda, Díaz-Martínez, \& Bravo-Ruiz, 2015). Por su parte, Muthiga \& McClanahan (2020) reportaron información reproductiva de $D$. setosum que resulta referencial para $D$. mexicanum sobre el tiempo embrionario (huevo pequeño de $67-92 \mu \mathrm{m}$, alcanza el estadio de blástula en 6 horas) y larvario (larva planctontrófica, alcanza el estadio de larva pluteus en 35 horas) en cultivos controlados a $26{ }^{\circ} \mathrm{C}$.

\section{Diadema antillarum (Selenka, 1867)}

\section{Clasificación: Echinoidea | Diadematoida| Diadematidae}

Distribución: El erizo de mar D. antillarum (Fig. 2i) es el herbívoro más abundante que se encuentra en el Océano Atlántico occidental tropical, incluido el Mar Caribe, el Golfo de México y las costas norte y este de América del Sur (hasta Brasil). También se encuentra en el Atlántico este en las Islas Canarias y el Océano Índico. Cuando la población de estos erizos de mar se encuentra en un nivel saludable, son los principales herbívoros que evitan el crecimiento excesivo de algas en el arrecife (Edmunds \& Carpenter, 2001).

País que lo cultiva: Belice (en avance).

Gestión en producción: El erizo de mar D. antillarum (al igual que su congénere del Pacífico, D. mexicanum) presenta un rol ecológico fundamental en la salud del ecosistema de coral (Alvarado, Cortés, \& Reyes-Bonilla, 2012). Existen varios estudios que muestran una extensa variación en el patrón reproductivo anual entre diferentes poblaciones del Atlántico occidental, a lo largo de su rango de distribución (Garrido, Haroun, \& Lessios, 2000). Se conoce que los erizos adultos son menos susceptibles a mortalidad por depredación, sino que también actúan para mejorar la supervivencia de los juveniles, a través del refugio del dosel de espinas. Sin embargo, la liberación a gran escala de erizos de mayor tamaño suficientemente grande con una densidad suficientemente alta es logísticamente complejo. Pese a la importancia que tienen los erizos Diadema para consumo de sus gónadas, existe principal interés de cultivarlo para restauración de los ecosistemas de coral (Muthiga \& McClanahan, 2020).

Avances al 2020: Aún no se ha desarrollado la tecnología de acuicultura para la cría de juveniles de D. antillarum (Rogers, 2011) 


\section{PERSPECTIVAS DEL CULTIVO DE EQUINODERMOS EN LATINOAMÉRICA}

La acuicultura es un sector estratégico de producción masiva de alimentos que permite mejorar la economía, competitividad y potenciar la capacidad de respuesta ante la seguridad alimentaria y el desarrollo sostenible entre las naciones latinoamericanas (FAO, 2020a; Tabla 1). Es considerada una frontera todavía sin límites a la vista para su desarrollo frente a las debilitadas pesquerías artesanales de libre acceso (FAO, 2020b). Por ello, es necesario que este sector diversifique la producción de organismos acuáticos comestibles (Tabla 2) para proveer proteína de alta calidad y de bajo costo, y con ello, promueva el consumo de nuevas opciones alimenticias de calidad y nutracéuticos, a través de recursos no tradicionales, pero de alto valor comercial (García, Rosas, \& Rodríguez-Morales, 2013).
El cultivo de los equinodermos, y en particular de pepinos de mar y erizos de mar en Latinoamérica es una industria en expansión que pudiera abastecer a los mercados asiáticos a escala global, resguardando la ecología al restaurar la pesca agotada a niveles sostenibles. Y por la característica geográfica de la región se podría desarrollar la acuicultura de pepino de mar y erizo de mar de modo exitoso en varios países, pero es una región que presenta condiciones ambientales altamente fluctuantes (Banks et al., 2011; Hilborn et al., 2020; Bertrand et al., 2020). Por lo que para realizar la acuicultura de varias especies de equinodermos es crucial conocer las condiciones físicoquímicas del agua y ambientales locales (Sachs \& Ladd, 2011). Existe información que sugiere la idea que estas condiciones por su variabilidad no actuarían igual en todas las regiones, ya que la tropicalización sería suavizada por la fenomenología local de alta frecuencia (i.e.,

TABLA 2

Listado de especies de erizos de mar, pepinos de mar y estrellas de mar comercializadas en las pesquerías de Latinoamérica. Asterisco corresponde a los países con regulación pesquera (plan de manejo) y que presentan pesca ilegal, no declarada, no regulada. Información tomada de Toral-Granda (2008)

\begin{tabular}{|c|c|c|c|c|}
\hline Grupo & Orden & Familia & Especies & Explotación comercial \\
\hline \multirow[t]{17}{*}{ Erizos de mar } & Camarodonta & Strongylocentrotidae & Strongylocentrotus purpuratus & México* \\
\hline & & & Mesocentrotus franciscanus & México* \\
\hline & & Toxopneustidae & Lytechinus pictus & México \\
\hline & & & Lytechinus variegatus & Venezuela \\
\hline & & & Tripneustes depressus & México, Ecuador, Perú \\
\hline & & & Tripneustes ventricosus & Cuba* \\
\hline & & & Toxopneustes roseus & México, Ecuador \\
\hline & & Echinometridae & Echinometra lucunter & \\
\hline & & Parechinidae & Loxechinus albus & Perú, Chile* \\
\hline & Arbacioida & Arbaciidae & Arbacia stellata & México, Ecuador \\
\hline & & & Arbacia dufresnii & Argentina \\
\hline & & & Arbacia punctulata & Venezuela, Brasil \\
\hline & & & Arbacia lixula & México, Brasil \\
\hline & Cidaroida & Cidaridae & Eucidaris tribuloides & $\begin{array}{l}\text { México, Belice, Panamá, } \\
\text { Colombia, Venezuela, } \\
\text { Brasil }\end{array}$ \\
\hline & Diadematoida & Diadematidae & Diadema mexicanum & $\begin{array}{l}\text { México, Costa Rica, } \\
\text { Ecuador }\end{array}$ \\
\hline & Clypeasteroida & Mellitidae & Encope micropora & México, Ecuador \\
\hline & & Clypeasteridae & Clypeaster europacificus & $\begin{array}{l}\text { México, Panamá, Costa } \\
\text { Rica, Ecuador, Perú. }\end{array}$ \\
\hline
\end{tabular}


TABLA 2 (Continuación)

\begin{tabular}{|c|c|c|c|c|}
\hline Grupo & Orden & Familia & Especies & Explotación comercial \\
\hline \multirow[t]{19}{*}{ Pepinos de mar } & \multirow[t]{5}{*}{ Synallactida } & \multirow[t]{5}{*}{ Stichopodidae } & Isostichopus badionotus & $\begin{array}{l}\text { Mexico*, Cuba**, } \\
\text { Nicaragua, Panamá, } \\
\text { Colombia*, Venezuela, } \\
\text { región del caribe }\end{array}$ \\
\hline & & & Isostichopus fuscus & $\begin{array}{l}\text { México*, Panamá*, } \\
\text { Ecuador*, Perú* }\end{array}$ \\
\hline & & & Stichopus horrens & Ecuador \\
\hline & & & Astichopus multifidus & $\begin{array}{l}\text { Panamá, Cuba, región del } \\
\text { caribe }\end{array}$ \\
\hline & & & Apostichopus parvimensis & México* \\
\hline & \multirow[t]{11}{*}{ Holothuriida } & \multirow[t]{11}{*}{ Holothuriidae } & $\begin{array}{l}\text { Holothuria (Halodeima) } \\
\text { mexicana }\end{array}$ & $\begin{array}{l}\text { Cuba*, Nicaragua, } \\
\text { Panamá, Venezuela }\end{array}$ \\
\hline & & & H. arenícola & Nicaragua \\
\hline & & & H. glaberrima & \\
\hline & & & H. grisea & \\
\hline & & & H. (Selenkothuria) theeli & Ecuador, Perú \\
\hline & & & H. impatiens & México \\
\hline & & & H. inornata & Costa Rica \\
\hline & & & H. kefersteini & Ecuador \\
\hline & & & H. atra & Ecuador \\
\hline & & & H. floridana & México*, Cuba \\
\hline & & & Actinopyga agassizi & Panamá, Venezuela \\
\hline & \multirow[t]{3}{*}{ Dendrochirotida } & \multirow[t]{3}{*}{ Cucumaridae } & Athyonidium chilensis & Perú, Chile \\
\hline & & & Pattalus mollis & Perú, Chile \\
\hline & & & Ocnus suspectus & \\
\hline \multicolumn{5}{|l|}{ Estrellas de mar } \\
\hline & \multirow[t]{6}{*}{ Valvatida } & Oreasteridae & Oreaster reticulatus & \\
\hline & & Ophidiasteridae & Pharia pyramidata & \\
\hline & & & Phataria unifascialis & \\
\hline & & Asterinidae & Asterina stellifera & \\
\hline & & Oreasteridae & Pentaceraster cumingi & \\
\hline & & & Nidorellia armata & \\
\hline & \multirow[t]{3}{*}{ Forcipulatida } & Heliasteridae & Heliaster helianthus & \\
\hline & & Stichasteridae & Stichaster striatus & \\
\hline & & Asteriidae & Pisaster ochraceus & \\
\hline
\end{tabular}

surgencias costeras) que mueven masas de agua fría enriquecida a la superficie, y esto contrastaría con aquellas regiones que no presentan influencia de surgencias (baja concentración de nutrientes y de oxígeno), durante los eventos ENOS (Vega, Vásquez, \& Buschmann, 2005; Arntz et al., 2006;). El tema ENOS debiera ser incorporado como un factor más de variabilidad interanual a la temática de producción acuícola en América Latina, ya que las especies nativas de equinodermos candidatas para la acuicultura son las que mejor estarían adaptadas a condiciones ambientales locales provocadas por intensas surgencias (Vásquez \& Alonso-Vega, 2004; Defeo et al., 2013). Todo esto explica la necesidad urgente de actualizar y ampliar el conocimiento sobre la biología básica y dinámica poblacional, especialmente en lo referente a aspectos reproductivos, crecimiento y reclutamiento, como base para adopción de medidas de regulación y protección de todas aquellas especies de equinodermos de 
interés comercial (Tabla 1) para la inserción y ajuste de nuevas tecnologías (i.e., Acuacultura Multitrófica Integrada).

En América Latina la investigación en acuicultura de equinodermos ha progresado mucho, y cada vez con mayor visibilidad e impacto en la comunidad científica internacional (Stotz, 2000; New, 2003; Lodeiros \& Freites, 2008; Bauer, 2016; Sonnenholzner, Alcívar, Márquez, \& Lodeiros, 2017; Sonnenholzner, Moreira, \& Panchana, 2019). Por eso, la filosofía productiva actual no son los monocultivos, sino los cultivos inteligentes, sustentables y ambientalmente eficientes con especies nativas, mediante la acuicultura multitrófica integrada: herbívoro - detritívoro - macroalgas (Chopin et al., 2001; Purcell, Bexter, \& Fuentes, 2013; Park et al., 2015) enfocándose en el cultivo para domesticación de un mayor número de especies nativas, por su alta potencialidad para apuntar a procesos más eficaces y dinámicos que permitan conseguir productos alimenticios resilientes de muy alta calidad y alcancen el máximo rendimiento sostenible de producción (Orensanz \& Jamieson, 1998; MEA, 2005). Siendo necesario evaluar primero el comportamiento de las especies de interés en cautiverio y sus respuestas ante las posibilidades de reproducción y producción controlada, y a futuro emprender programas de cierre del ciclo reproductivo con mejoramiento genético, y repoblamiento a escala regional (generando cero dependencias de animales extraídos de poblaciones naturales debilitadas). Este trabajo destacó a 17 especies de equinodermos comerciales, principalmente pepinos y erizos de mar. Sin embargo, también existe la alta demanda de estrellas de mar de Centroamérica y del Caribe para el mercado asiático; no en grandes cantidades (a diferencia de los pepinos de mar y los erizos de mar) pero la demanda está ahí (Castrejón \& Bucaram, 2020). Por este motivo, es necesario que provoquemos un nuevo modelo productivo acuícola que amplifique hacia la diversificación, considerando especies nativas de equinodermos para generación de una acuicultura ambientalmente responsable y equilibrada que preserve las poblaciones naturales. De estas 17 especies de equinodermos, tres son referentes mundiales, el pepino de mar I. fuscus de Ecuador (Fig. 1c; Tabla 3) y los dos erizos de mar, A. dufresnii de Argentina (Fig. 2a) y L. albus de Chile (Fig. 2c). Se distinguen por su muy alta cualificación para la acuicultura: $i$ ) fácil de cultivar, $i i)$ rápido crecimiento, iii) elevada bioproducción versus tamaño y conversión alimenticia, iv) excelente calidad nutritiva, $v$ ) alto valor agregado en nutracéutica, $v i$ ) existen avances en domesticación, y vii) relevancia en lo ambiental para fines de repoblación y reciclaje de la carga orgánica y secuestro de carbono (Lawrence, 2007; Purcell, Conand, Uthicke, \& Byrne, 2016). Con la pandemia del Covid-19 y el retraso en la economía mundial, en el sector acuícola hay lecciones transformadas en aprendizaje e innovaciones para el emprendimiento exitoso del cultivo multitrófico de pepinos y erizos de mar nativos bien posicionadas en el mercado para asegurar su sostenible producción, consumo y venta que satisfagan el incremento en la demanda de productos cultivados del mar para los próximos 30 años. Pero se necesita ingentes esfuerzos para promover mayores inversiones de dinero de los

TABLA 3

Información resumen del estado de conocimiento en acuicultura de las tres especies de pepino de mar mejor cotizadas en el mundo (Com. Pers. Lovatelli, 2020)

\begin{tabular}{lccc}
\multicolumn{4}{c}{ Especies de pepinos de mar comerciales } \\
Número de publicaciones & Isostichopus fuscus & Holothuria scabra & Apostichopus japonicus \\
Desde 1990 & 737 & 2774 & 10832 \\
Por año & 6 & 24 & 94 \\
Peer Review por año & 5 & 8 & 62 \\
Acuicultura & $<0,1$ & 1 & 28 \\
\hline
\end{tabular}


productores del sector privado que acoja y operativice sistemas innovadores de producción acuícola masiva de alimentos funcionales con el acompañamiento de desarrollo tecnológico con orientación hacia la Investigación + Desarrollo + innovación $(\mathrm{I}+\mathrm{D}+i)$, junto con la producción de nuevos protocolos optimizados de cultivos domesticados o mejorados que generen el aumento de alimento de calidad, mediante la Revolución Azul (Hulata, 2001; Boyd, McNevin, Clay, \& Johnson, 2005; Ahmed \& Thompson, 2019; FAO, 2020a) que implica lo siguiente: 1) diseño y puesta en marcha de programas y proyectos de investigación que permitan amplificar la diversificación productiva en acuicultura multitrófica para la cría del pepino de mar y erizo de mar, basándose en programas regionales de reproducción controlada continua por más de 3 generaciones y de repoblación de bancos naturales; 2) apertura de centros de criaderos de pepinos y erizos de mar que permitan establecer y generar sostenimiento de nuevas actividades productivas de tipo recreativo, educativo y comercial. Se impulsarían actividades de cultura ambiental e investigativas integrales a nivel nacional articulados a centros de formación académica costeros; 3 ) promoción de gastronomía local como cultura por el consumo de alimentos saludables de excelente calidad de proteínas presentes en pepinos y erizos de mar en el ámbito de la alimentación; 4) adecuación de laboratorios para producción de juveniles de pepinos de mar y erizos de mar. La producción comercial de pepinos de mar en criaderos y el cultivo asociado a canales o estanques (o piscinas) de camarones en granjas marinas con base en el mar para algas marinas, ostras/ mejillones, y peces son económicamente atractivas y respetuosas con el medio ambiente.

Declaración de ética: los autores declaran que todos están de acuerdo con esta publicación y que han hecho aportes que justifican su autoría; que no hay conflicto de interés de ningún tipo; y que han cumplido con todos los requisitos y procedimientos éticos y legales pertinentes. Todas las fuentes de financiamiento se detallan plena y claramente en la sección de agradecimientos. El respectivo documento legal firmado se encuentra en los archivos de la revista.

\section{AGRADECIMIENTOS}

El autor agradece a Roberto Aguilera Alfaro, Juan Manuel Estrada, Luis Antonio Felaco, Andrés Goldin, Arlenie Rogers, Guiherme Rupp, Christian Vela-Gallo y Carlos Vergara-Cheny por la información compartida y a los revisores anónimos por la lectura del manuscrito.

\section{RESUMEN}

Introducción: La acuicultura de equinodermos en América Latina es incipiente, pero representa una nueva frontera para la producción de alimentos marinos altamente nutritivos, con especies nativas de alto valor comercial que ofrecen un gran potencial en comparación con las debilitadas pesquerías bentónicas artesanales. Metodología: Se revisó la literatura sobre pepinos de mar, erizos de mar y estrellas de mar hasta el año 2020. Resultados: Para el 2020, había 17 especies nativas con importantes avances en reproducción, larvicultura, crecimiento, tratamiento e identificación de enfermedades y nutrición en México, Belice, Panamá, Colombia, Ecuador, Perú, Brasil, Chile y Argentina. Conclusiones: La acuicultura de equinodermos en América Latina está avanzando y se beneficiaría de los sistemas multitróficos para expandirse y diversificarse, reduciendo la presión sobre las pesquerías agotadas.

Palabras clave: pepinos de mar, erizos de mar, estrella de mar, acuicultura integral multitrófica.

\section{REFERENCIAS}

Agudelo-Martínez, V., Vergara-Hernández, W., VillazónTurizo, M., Pabón-Caro, L., \& Rodríguez- Forero, A. (2016). Manual para el cultivo y procesamiento de pepino de mar. Primera Edición, Santa Marta, Universidad del Magdalena.

Agüero, M. (ed.) (2007). Capacidad de pesca y manejo pesquero en América Latina y el Caribe. FAO Documento Técnico de Pesca. No. 461. Roma, FAO. 403p

Ahmed, N., \& Thompson, S. (2019). The blue dimensions of aquaculture: A global synthesis. Science of the Total Environment, 652, 851-861.

Alvarado, J.J., Cortés, J., \& Reyes-Bonilla, H. (2012). Reconstruction of Diadema mexicanum bioerosion 
impact on three Costa Rican Pacific coral reefs. Revista de Biología Tropical, 60, 121-132.

Alves, R.R.N., Oliveira, T.P.R., Rosa, I.L., \& Cunningham, A.B. (2013). Marine Invertebrates in Traditional Medicines. En: R. Alves, \& I. Rosa, (Eds.), Animals in Traditional Folk Medicine (pp. 263-287). Springer, Berlin, Heidelberg.

Andrew, N.L., Agatsuma, Y., Ballesteros, E., Bazhin, E., Creaser, E.P., Barnes, D.K., Botsford, L.W., Bradbury, A., Campbell, A., Dixon, J.D., Einarsson, S., Gerring, P.K., Hebert, K., Hunter, M., Hur, S.B., Johnson, C.R., Juinio-Meñez, M.A., Kalvass, P., Miller, R.J., Moreno, C.A., Palleiro, J.S., Rivas, D., Robinson, S.M.L., Schroeter, S.C., Steneck, R.S., Vadas, R.L., Woodby, D.A., \& Xiaoqi, Z. (2002). Status and management of world sea urchin fisheries. Oceanography and Marine Biology - Annual Review, 40, 343-425.

Arias, E., Barahona, N., Lozada, E., \& Jerez, G. (1994). Monitoreo de la pesquería del recurso erizo en la X y XI Regiones. Informe Técnico final del Instituto de Fomento Pesquero, FIP-IT/93-13, Chile, 74 pp.

Arntz, W.E., Gallardo, V.A., Gutiérrez, D., Isla, E., Levin, L.A., Mendo, J., Neira, C., Rowe, G.T., Tarazona, J., \& Wolf, M. (2006). El Niño and similar perturbation effects on the benthos of the Humboldt, California, and Benguela Current upwelling ecosystems. Advances in Geosciences, European Geosciences Union, $6,243-265$

Arreguín-Sánchez, F. (2009). Cambio climático y el colapso de la pesquería de camarón rosado (Farfantepenaeus duorarum) de la sonda de Campeche. En: E. Rivera-Arriaga, I. Azuz-Adeath, G.J. Villalobos Zapata, \& L. Alpuche Gual (Eds.). Cambio climático en México un enfoque costero-marino (pp. 399-410). Universidad Autónoma de Campeche.

Asha, P.S., \& Muthiah, P. (2005). Effects of temperature, salinity and $\mathrm{pH}$ on larval growth, survival and development of the sea cucumber Holothuria spinifera Theel. Aquaculture, 250, 823-829.

Ayerbe, R., Zeballos, S., Castañeda, V., Lope, F., Bendita, H., Vizcarra, Y., \& Sanz, L. (2018). Manual: Cultivo de erizo comercial Loxechinus albus en la Región Moquegua. Informe Instituto del Mar del Perú, 45, 210-241.

Azari, D., Giraspy, B., \& Walsalam, I. (2010). Aquaculture potential of the tropical sea cucumbers Holothuria scabra and $H$. lessoni in the Indo-Pacific region. SPC Beche-de-mer Informative Bulletin, 30, 29-32.

Banks, S., Edgar, G., Glynn, P., Kuhn, A., Moreno, J., Ruiz, D., Schuhbauer, A., Tiernan, J.P., Tirado, N., \& Vera M. (2011). A review of Galápagos marine habitats and ecological processes under climate change scenarios. En: I. Larrea, \& G. Di Carlo (Eds.), Climate change vulnerability assessment of the Galápagos
Islands (pp. 47-68). WWF and Conservation International, USA.

Barbieri, E.S., Rubilar, T., Gázquez, A., Avaro, M., Seiler, E.N., Vera-Piombo, M., Gittardi, A., Chaar, F., Fernandez, J.P., \& Sepulveda, L. (2020). Sea urchin pigments as potential therapeutic agents against the spike protein of SARS-CoV-2 based on in silico analysis. ChemRxiv.

Bascompte, J., \& Jordano, P. (2007). Plant-animal mutualistic networks: The architecture of biodiversity. Annual Review of Ecology Evolution and Systematics, 38, 567-93.

Battaglene, S., Seymour, J.E., \& Ramofafia, C. (1999). Survival and growth of cultured juvenile sea cucumbers, Holothuria scabra. Aquaculture, 178, 293-322.

Bauer, J. (2016). Co-cultivo de abulón azul Haliotis fulgens y pepino de mar Parastichopus parvimensis en isla Natividad, BCS - México. Tesis de Biología Marina, Universidad Autónoma de Baja California Sur, México, 63 pp.

Becker P., Eeckhaut I., Ycaza R.H., Mercier A., \& Hamel J.-F. (2009). Enfermedad por protozoos en cultivo larvario de pepino de mar comestible Isostichopus fuscus. En: L.G. Harris, S.A. Bottger, C.W. Walker, \& M.P. Lesser (Eds.), Echinoderms (pp. 571-573), CRC Press, Londres.

Benítez-Villalobos, F., Hernando Ávila-Poveda, O., DíazMartínez, J.P., \& Bravo-Ruíz, A. (2015). Gonad development stages and reproductive traits of Diadema mexicanum (Echinodermata: Echinoidea) from Oaxaca, México, Invertebrate Reproduction \& Development, 59, 237-249.

Berkes, F., Mahon, R., McConney, P., Pollnac, R., \& Pomeroy, R. (2001). New directions: A vision form small scale fisheries. En: F. Berkes, R. Mahon, P. McConney, R. Pollnac, \& R. Pomeroy (Eds.), Managing small scale fisheries: Alternative directions and methods (pp. 223-228). International Development Research Centre, Ottawa.

Bertrand, A., Lengaigne, M., Takahashi, K., Avadí, A., Poulain, F. \& Harrod, C. (2020). El Niño Southern Oscillation (ENSO) effects on fisheries and aquaculture. FAO Fisheries and Aquaculture Technical Paper No. 660. Rome, FAO.

Boni, M.F., Lemey, P., Jiang, X., Lam, T.T-Y., Perry, B.W., Castoe, T.A., Rambaut, A., \& Robertson, D.L. (2020). Evolutionary origins of the SARS-CoV-2 sarbecovirus lineage responsible for the COVID19 pandemic. Nature microbiology doi.org/10.1038/ s41564-020-0771-4.

Botsford, L.W., Castilla, J.C., \& Peterson, C.H. (1997). The management of fisheries and marine ecosystems. Science, 277, 509-515. 
Boyd, C.E., McNevin, A.A., Clay, J.W., \& Johnson, H.M. (2005). Certification issues for some common aquaculture species. Reviews in Fisheries Science, 13, 231-279.

Boyd, C.E., D’Abramo, L.R., Glencross, B.D., Huyben, D.C., Juarez, L.M., Lockwood, G.S., McNevin, A.A., Tacon, A.G.J., Teletchea, F., Tomasso Jr., J.R, Tucker, C.S., \& Valentin, W.C. (2020). Achieving sustainable aquaculture: Historical and current perspectives and future needs and challenges. Journal of the World Aquaculture Society, 51, 578-633.

Buitrago, J., \& Boada, J. (1996). La pesca de la holoturia Isostichopus badionotus en el oriente de Venezuela. Memoria - Sociedad de Ciencias Naturales La Salle, 56, 33-40.

Burchardt, H.-J. (2017). La crisis actual de América Latina: causas y soluciones. Nueva Sociedad 267, 114-128.

Caddy, J.F., \& Defeo, O. (2003). Enhancing or restoring the productivity of natural populations of shellfish and other marine invertebrate resources. FAO Fisheries Technical Paper 448, FAO, Roma: 159 pp.

Caso, M.E. (1971). Contribución al estudio de los holoturoideos de México. Morfología externa e interna y ecología de Holothuria grisea Selenka. Anales del Instituto de Biología, Universidad Nacional Autónoma de México. Serie de Ciencias del Mar y Limnología, 42, 31-40.

Castilla, J. (1990). El erizo chileno Loxechinus albus: importancia pesquera, historia de vida, cultivo en laboratorio y repoblación natural. Cultivos de moluscos en América Latina, 83-96.

Castilla, J.C., \& Defeo, O. (2001). Latin-American benthic shellfisheries: Emphasis on co-management and experimental practices. Reviews in Fish Biology and Fisheries, 11, 1-30.

Castrejón, M., \& Charles, T. (2013). Improving fisheries co-management through ecosystem-based spatial management: The Galápagos Marine Reserve. Marine Policy, 38, 235-245.

Castrejón, M., \& Bucaram, S. (2020). Diagnóstico integral del sector pesca y acuicultura de la República de Panamá. Banco Interamericano de Desarrollo. 194 pp.

CELAC (2020). Plan para la seguridad alimentaria, nutrición y erradicación del hambre de la CELAC 2025 Resumen Ejecutivo, 9 pp. FAO/CEPAL/ALADI, I4493S $/ 1 / 03.15$

CEPAL (2020). América Latina y el Caribe ante la pandemia del COVID-19: efectos económicos y sociales, Informe Especial COVID-19, $\mathrm{N}^{\circ} 1,3$ de abril, Santiago.
Chen, J., \& Chang, Y. (2015). Sea cucumber aquaculture in China. En: N. Brown, \& S. Eddy (Eds.), Echinoderm Aquaculture (pp. 317-330). John Wiley \& Sons, Inc.

Cheng, L.J., Zhu, J., Abraham, J., Trenberth, K.E., Fasullo, J.T., Zhang, B., Yu, F., Wan, L., Chen, X., \& Song, X. (2019). 2018 continues record global ocean warming. Advances in Atmospheric Sciences, 36, 249-252.

Cheng, L., Abraham, J., Hausfather, Z., \& Trenberth, K.E. (2019). How fast are the oceans warming? Science, $363,128-129$.

Choo, P.S. (2008). Population status, fisheries and trade of sea cucumbers in Asia. En: V. Toral-Granda, A. Lovatelli, \& M. Vasconcellos (Eds.), Sea Cucumbers A Global Review of Fisheries and Trade. FAO Fisheries and Aquaculture Technical Paper No 516. FAO; Rome, Italy.

Chopin, T., Buschmann, A.H., Halling, C., Troell, M., Kautsky, N., Neori, A., \& Neefus, C. (2001). Integrating seaweeds into marine aquaculture systems: A key toward sustainability. Journal of Phycology, 37, 975-986.

Chuenpagdee, R., Morgan, L.E., Maxwell, S.M., Norse, E.A., \& Pauly, D. (2003). Shifting gears: assessing collateral impacts of fishing methods in US waters. Frontiers in Ecology and the Environment, 1, 517-524.

Conand, C. (2001). Overview over the last decade of sea cucumber fisheries: what possibilities for a durable management? En: M. Barker (Ed.), Echinoderms 2000 (pp. 339-344), Proceedings of the 10th International Conference. A. A. Balkema, Rotterdam, Holanda.

Conand, C. (2004). Present status of world sea cucumber resources and utilization: An international overview. En: A. Lovatelli, C. Conand, S. Purcell, S. Uthicke, J-F. Hamel, \& A. Mercier (Eds.), Advances in Sea Cucumber Aquaculture and Management (pp.13-24). FAO, Rome, Fisheries Technical Paper, No. 463.

Cox, G.C. (1999). Alien species in North America and Hawaii. Impacts on Natural Ecosystems. Island Press, Washington, DC., 400 pp.

Cuesta-Gómez, D.M., Lazo, J.P., \& Sánchez-Saavedra, M.D.P. (2020). Effects of dietary fish oil and soya bean lecithin on gonad index, color and biochemical composition of the purple sea urchin, Strongylocentrotus purpuratus (Stimpson 1857). Aquatic Research, 00,1-19.

Da Costa, P.B. (2010). Sobreviviencia, crecimiento y capacidad de reciclaje de materia orgánica del pepino de mar Holothuria grisea Selenka, 1867 (Echinocdermata: Holothuroidea: Aspidochirotida). Disertación Tesis de Maestría, Centro de Ciencias Agrarias, Departamento de Acuicultura, Florianopolis 47 pp. 
Defeo, O., McClanahan, T., \& Castilla, J.C. (2007). A brief history of fisheries management and societal roles. En: T. McClanahan, \& J.C. Castilla (Eds.), Fisheries management: Progress towards sustainability (pp. 3-21). Blackwell, Londres.

Defeo, O., Castilla, J., \& Castrejón, M. (2009). Pesquerías artesanales de invertebrados en América Latina: paradigmas emergentes de manejo y gobernanza. Foro Iberoamericano de Recursos Marinos y Acuicultura, 2, 89-117.

Defeo, O., Castrejón, M., Ortega, L., Kuhn, A.M., Gutiérrez, N.L., \& Castilla, J.C. (2013). Impacts of climate variability on Latin American small-scale fisheries. Ecology and Society, 18, 30 .

De Moya-Anegón, F., Herrán-Páez, E., Bustos-González, A., Corera-Álvarez, E., Tibaná-Herrera, G., \& Rivadeneyra, F. (2020). Ranking iberoamericano de instituciones de educación superior 2020 (SIR Iber), Granada: Ediciones Profesionales de la Información. ISBN: 97884-120239-30.

De Silva, S. (1989). Exotic organisms in Asia. Asian Fisheries Society Special Publication 3, Manila, Philippines, $154 \mathrm{pp}$.

De Silva, S., Nguyen, T.T., Turchini, G.M., Amarasinghe, U.S., \& Abery, N.W. (2009). Alien species in aquaculture and biodiversity: A paradox in food production, Ambio, 38:24-28.

De Zoysa, M. (2012). Medicinal benefits of marine invertebrates: Sources for discovering natural drug candidates. En: S.K. Kim (Ed.), Advances in Food and Nutrition Research, 65, 153-169. Elsevier, New York.

Del Valle-García, R., Abreu-Pérez, M., Solís-Marín, F.A., \& Laguarda-Figueras, A. (2013). Echinoderm of the Cuban Archipelago. En: J.J. Alvarado, \& F.A. SolísMarín (Eds.), Echinoderm Research and Diversity in Latin America (pp. 403-424). Springer-Verlag Berlin Heidelberg.

Díaz-Martínez, J.P. (2019). Biología reproductiva, desarrollo larvario y efecto de la acidificación del océano en el éxito de la fertilización y desarrollo embrionario de Arbacia stellata (Blainville, 1825) (ECHINODERMATA: ECHINOIDEA). Tesis doctoral en Ecología Marina, Universidad del Mar, Puerto Escondido, Oaxaca - México. 148 pp.

DOF-SEGOP (2015). Acuerdo por el que se da a conocer el Plan de Manejo Pesquero del pepino de mar café (Isostichopus badionotus) y lápiz (Holothuria floridana) en la península de Yucatán. Diario Oficial, $12 / 05 / 2015$.

Edmunds, P.J., \& Carpenter, R.C. (2001). Recovery of Diadema antillarum reduces macroalgal cover and increases abundance of juvenile corals on a Caribbean reef. Proceedings of the National Academy of Sciences, 98, 5067-5071.
Edwards, P., Zhang, W., Belton, B., \& Little, D.C. (2019). Misunderstandings, myths, and mantras in aquaculture: Its contribution to world food supplies has been systematically over reported. Marine Policy, 106, 103547.

Fajardo-León, M.C., Suárez-Higuera, M.C.L., del ValleManríquez, A., \& Hernández-López, A. (2008). Reproductive biology of the sea cucumber Parastichopus parvimensis (Echinodermata: Holothuroidea) at Isla Natividad and Bahía Tortugas, Baja California Sur, México. Ciencias Marinas, 34, 165-177.

FAO-FishStatJ (2019a). Global capture production 1950-2015. En: Fisheries and aquaculture software. FishStatJ - Software for Fishery and Aquaculture Statistical Time Series. FAO Fisheries and Aquaculture Department. Rome.

FAO-FishStatJ (2019b). Fisheries and aquaculture software. FishStatJ - Software for Fishery and Aquaculture Statistical Time Series. FAO Fisheries and Aquaculture Department. Rome.

FAO/OMS (2003). Programa conjunto FAO/OMS sobre normas alimentarias comisión del Codex Alimentarius $26^{\circ}$ período de sesiones Roma, Italia, 30 de junio -7 de julio de 2003

FAO (2012) Commercially important sea cucumbers of the world. FAO Species Catalogue for Fishery Purposes. Rome: Food and Agriculture Organization, United Nations.

FAO (2020a). Factsheets on the 21 SDG indicators under FAO custodianship. A highlight of the main indicators with the greatest gaps in country reporting. Rome.

FAO (2020b). Globefish highlights July 2020, issue, with Jan - Mar 2020 Statistics - A quaterly update on world seafood markets. Globefish Highlights No. 3-2020. Rome

Ferdouse, F. (2004). World markets and trade flows of sea cucumber / beche-de-mer. En: A. Lovatelli, C. Conand, S. Purcell, S. Uthicke, J.F Hamel, \& A. Mercier (Eds.), Advances in Sea Cucumber Aquaculture and Management. FAO, Rome.

Fernández, M. (1998). Ecología de Athyonidium chilensis (Semper, 1868) (Echinodermata: Holothuroidea) en tres hábitats de la región de Coquimbo. Tesis para optar al título de Biólogo Marino, Universidad Católica del Norte, pp 73.

Fernández, V. (2007). Efecto de la proporción de proteína vegetal y animal en la dieta de ejemplares adultos de Athyonidium chilensis (Semper, 1868) (Echinodermata: Holothuridae) sobre el crecimiento y la distribución de los nutrientes alimentarios. Tesis para optar al título de Biólogo Marino, Universidad de Valparaíso, pp 46. 
FSIN (Food Security Information Network) (2020). Global Report on Food Crisis. Joint analysis for better decisions.

García, E., Rosas, C., \& Rodríguez-Morales, S. (2013). Uso eficiente de los recursos pesqueros y acuícolas: extracción de moléculas bioactivas de los subproductos para su empleo en el sector farmacéutico. En: L. Cruz-Suárez, D. Ricque-Marie, M. TapiaSalazar, M.G. Nieto-López, D. Villarreal-Cavazos, J. Gamboa-Delgado, \& C. Álvarez-González (Eds.), Contribuciones recientes en alimentación y nutrición acuicola (pp. 224-237). Universidad Autónoma de Nuevo León, San Nicolás de los Garza, Nuevo León, México.

Garrido, M.J., Haroun, R.J., \& Lessios, H.A. (2000). Annual reproductive periodicity of the sea urchin Diadema antillarum Philippi in the Canary Islands. Bulletin of Marine Science, 67, 989-996.

Giraspy, D.A.B., \& Ivy, G. (2005). Australia's first commercial sea cucumber culture and sea ranching project in Hervey Bay, Queensland, Australia. SPC Beche-de-Mer Information Bulletin, 21, 29-31.

Gómez-León, J., López-Navarro, J.L., Cerón Benavides, S.M., Roa-Méndez, J.F., \& Santos-Acevedo, M. (2015). Programa acuicultura sostenible para el Departamento del Magdalena. INVEMAR. Informe Técnico Final PYR-VAR-006-14. Santa Marta Colombia. $275 \mathrm{p}$.

González, E. (2006). Efecto de dietas naturales sobre el crecimiento y sustratos energéticos de los principales componentes corporales del pepino de mar Athyonidium chilensis. Tesis para optar al título de Biólogo Marino, Universidad Católica del Norte, pp 31.

Gopal, R., Vijayakumaran, M., Venkatesan, R., \& Kathiroli, S. (2008). Marine organisms in Indian medicine and their future prospects. Natural Product Radiance, $7,139-145$

Guisado, Ch., Carrasco, S.A., Díaz-Guisado, D., Maltrain, R., \& Rojas, H. (2012). Embryonic development, larval morphology and juvenile growth of the sea cucumber Athyonidium chilensis (Holothuroidea: Dendrochirotida). Revista de Biología Marina y Oceanografia 47, 65-73.

Guzmán, H., \& Guevara, C. (2002). Population structure, distribution and abundance of three commercial species of Sea Cucumber (Echinodermata) in Panamá. Caribbean Journal of Science, 38: 230-238.

Guzmán, H., Guevara, C., Hernández, I. (2003). Reproductive cycle of two commercial species of sea cucumber (Echinodermata: Holothuroidea) from Caribbean Panamá. Marine Biology, 142, 271-279.

Hadel, F.V., Monteiro, A.M.V., Ditadi, A.S.F., Tiago, C.G., \& Tommasi, L.R. (1999). Invertebrados marinhos: Echinodermata. En: C.A., Joly, \& C.E.M. Bicudo
(Eds.), Biodiversidade do Estado de São Paulo, Brasil: sintese ao conhecimento ao final do século $X X, 3$. FAPESP.

Hamel, J.-F, Ycaza-Hidalgo, R., \& Mercier, A. (2003). Larval development and juvenile growth of the Galápagos sea cucumber Isostichopus fuscus. SPC Beche-de-mer Information Bulletin, 18, 3-8.

Hendler, G., Miller, J.E., Pawson, D.L., \& Kier P.M. (1995). Sea stars, sea urchins, and allies. Smithsonian Institution Press, Washington, DC.

Hilborn, R., Amoroso, R.O., Anderson, C.M., Baum, J.K., Branch, T.A., Costello, C., de Moor, C.L., Faraj, A., Hively, D., Jensen, O.P., Kurota, H., Little, L.R., Mace, P., McClanahan, T., Melnychuk, M.C., Minto, C., Osio, G.C., Parma, A.M., Pons, M., Segurado, S., Szuwalski, C.S., Wilson, J.R., \& Ye, Y. (2020). Effective fisheries management instrumental in improving fish stock status. Proceedings of the National Academy of Sciences, 117, 2218-2224.

Hooker, Y., Prieto-Ríos, E., \& Solís-Marín, F.A. (2013). Echinoderms of Peru. En: J.J. Alvarado, \& F.A. SolísMarín (Eds.), Echinoderm Research and Diversity in Latin America (pp. 277-299). Springer-Verlag Berlin Heidelberg.

Hulata, G. (2001). Genetic manipulations in aquaculture: A review of stock improvement by classical and modern technologies. Genetics, 111, 155-173.

Inui, M. (2008). Dentoutekina uni riyou. En: D. Fujita, Y. Machiguchi, \& H. Kuwahara (Eds.), Recovery from urchin barrens - ecology, fishery, and utilization of sea urchins (pp. 223-229). Seizando-Shoten, Tokyo.

James, D.B., Gandhi, A.D., Palaniswamy, N., \& Rodrigo, J.X. (1994). Hatchery techniques and culture of the sea-cucumber Holothuria scabra. En: K. Rengarajan (Ed.), CMFRI Special Publication. Cochin. Central Marine Fisheries Research Institute. Kochi, India.

Junior, J., Ponte, I., Coe, C.M., Farías, W.R.L., Feitosa, C.V., Hamel, J.-F, \& Mercier, A. (2017). Sea cucumber fisheries in Northeast Brazil. SPC Beche-de-mer Information Bulletin, 37, 43-47.

Katow, H., Okumura, S., Sakai, Y., \& Shibuya, C. (2015). Sea cucumber farming in Japan, In: N. Brown, \& S. Eddy (Eds.), Echinoderm Aquaculture (pp. 287-316), John Wiley \& Sons, Inc

Kim, S.K., \& Himaya, S.W.A. (2013). Edible marine invertebrates: A promising source of nutraceuticals. En: S.K. Kim (Ed.), Marine nutraceuticals: Prospects and perspectives (pp. 243-256). CRC.

Lango-Reynoso, F., Castañeda-Chávez, M., Zamora-Castro, J.E., Hernández-Zárate, G., Ramírez-Barragán, M.A., \& Solís-Morán, E. (2012). Ornamental marine 
fishkeeping: A trade of challenges and opportunities. Latinoamerican Journal Aquatic Research, 40, $12-21$.

Lawrence J.M. (2007). Edible sea urchins: biology and ecology. Second edition. Developments in Aquaculture and Fisheries. Sciencie, 37. Elsevier.

Livengood, E.J., \& Chapman, F.A. (2007). The ornamental fish trade: An introduction with perspectives for responsible aquarium fish ownership. The Institute of Food and Agricultural Sciences IFAS Extension, Department of Fisheries and Aquatic Science. Florida Cooperative Extension Service. University of Florida.

Lodeiros, C., \& Freites, L. (2008). Estado actual y perspectivas del cultivo de moluscos bivalvos en Venezuela, En: A. Lovatelli, A. Farias, \& I. Uriarte (Eds.), Estado actual del cultivo y manejo de moluscos bivalvos y su proyección futura: factores que afectan su sustentabilidad en América Latina (pp.135-150). FAO Actas de Pesca y Acuicultura. Roma, Italia.

Lodeiros, C., Martín, A., Francisco, V., Noriega, N., Díaz, Y., Reyes, J., Aguilera, O., \& Alió, J. (2013). Echinoderms from Venezuela: Scientific recount, diversity and distribution. En: J.J. Alvarado, \& F.A. Solís-Marín (Eds.), Echinoderm Research and Diversity in Latin America (pp. 235-275). Springer-Verlag Berlin Heidelberg.

López-Luján, L., Solís-Marín, F.A., Zúñiga-Arellano, B., Caballero-Ochoa, A.A., Conejeros Vargas, C.A., CaoRomero, C.M., \& Méndez, I.E. (2020). Del océano al altiplano: las estrellas marinas del templo mayor de Tenochtitlan. Revista Arqueología Mexicana, 150, 68-76.

Maltrain, R. (2007). Crecimiento de Athyonidium chilensis (Semper, 1868) (Echinodermata: Holothuroidea) en cautiverio y policultivo con Eurhomalea lenticularis (Sowerby, 1835). Tesis para optar al título de Biólogo Marino, Universidad Católica del Norte, pp 49.

Maluf, L.Y. (1988). Composition and distribution of the central eastern Pacific echinoderms. Natural History Museum of Los Angeles County, 2, 1-242.

McClanahan, T., Castilla, J.C., White, A., \& Defeo, O. (2009). Healing small-scale fisheries by facilitating complex socio-ecological systems. Reviews in Fish Biology and Fisheries, 19, 33-47.

Mercier A., Ycaza R.H., \& Hamel J-F. (2004). Acuicultura del pepino de mar de Galápagos, Isostichopus fuscus. En: A. Lovatelli, C. Conand, S. Purcell, S. Uthicke, J.-F. Hamel, \& A. Mercier (Eds.), Avances en la acuicultura y gestión de manejo en acuacultura del pepino de mar (pp. 347-358). Documento técnico, 463. FAO.

Mercier, A., Ycaza, R.H., Espinoza, R.E., Arriaga-Haro, V.M., \& Hamel, J.-F. (2012). Hatchery experience and useful lessons from Isostichopus fuscus in Ecuador and Mexico. ACIAR Proceedings, 106, 79-90.

Mercier, A., Hamel, J.-F., Alvarado, J.J., Paola Ortiz, E., Benavides, M., \& Toral-Granda, T.-G. (2013). Apostichopus parvimensis. The IUCN Red List of Threatened Species:e.T180368A1621102. https:// dx.doi.org/10.2305/IUCN.UK.20131.RLTS. T180368A1621102.en.

Mercier, A., Ycaza, R.H., Espinoza, R., Arriaga Haro, V.M., \& Hamel, J.F. (2014). Hatchery experience and useful lessons from Isostichopus fuscus in Ecuador and Mexico. In: C.A. Hair, T.D. Pickering, \& D.J. Mills (Eds.), ACIAR Proceedings No. 136 (pp.79-90), Noumea, New Caledonia: Australian Center for International Agricultural Research, Cranberra, Australian Capital Territory, Australia.

Micael, J., Alves, M.J., Costa, A.C., \& Jones, M.B. (2009). Exploitation and Conservation of Echinoderms. Oceanography and Marine Biology: An Annual Review, 47, 191-208.

MEA (Millennium Ecosystem Assessment) (2005). Ecosystems and human well-being: Biodiversity synthesis. Washington (DC): World Resources Institute.

Moreno, C. (2002). Aspectos reproductivos de Athyonidium chilensis (Semper, 1868) (Echinodermata: Holothuroidea) en playa el Francés, IV Región, Chile. Tesis para optar al título de Biólogo Marino, Universidad Católica del Norte, pp. 38.

Moyle, P.B., \& Leidy, R.A. (1992). Loss of biodiversity in aquatic ecosystems; evidence from fish faunas. En: P.L. Fielder, \& S.K. Jain (Eds.), Conservation Biology: The Theory and Practice of Nature Conservation (pp.129-161), Chapman and Hall, London.

Muthiga, N.A., \& McClanahan, T.R. (2020). Diadema. En: J.M. Lawrence (Ed.), Sea urchins: Biology and Ecology (pp. 257-274), Elsevier.

Naylor, R.L., Williams, S.L., \& Strong, D.R. (2001). Aquaculture - a gateway for exotic species. Science, 294, 1655-1666.

New, M.B. (2003). Responsible aquaculture: Is this a special challenge for developing countries? World Aquaculture Society, 34, 26-31.

Orensanz, J., \& Jamieson, G.S. (1998). The assessment and management of spatially structured stocks: An overview of the North Pacific Symposium on Invertebrate Stock Assessment and Management. Canadian Special Publication of Fisheries and Aquatic Sciences, 125, 441-459.

Orensanz, J., Parma, A.M., Jerez, G., Barahona, N., Montecinos, M., \& Elias, I. (2005). What are the key elements for the sustainability of "S-fisheries" insights from South America. Bulletin of Marine Science, 76, 527-556. 
Paltzat, D.L., Pearce, C.M., Barnes, P.A., \& McKinley, R.S. (2008). Growth and production of California sea cucumbers (Parastichopus californicus Stimpson) co-cultured with suspended Pacific oysters (Crassostrea gigas Thunberg), Aquaculture, 275,124-137.

Park, H.J., Han, E., Lee, W.C., Kwak, J.H., Kim, H.C., Park, M.S., \& Kang, C.-K. (2015). Trophic structure in a pilot system for the integrated multi-trophic aquaculture off the east coast of Korean peninsula as determined by stable isotopes. Marine Pollution Bulletin, 95, 207-214.

Pawson, D.L., Vance, D.J., Messing, C.G., Solís-Marín, F.A., \& Mah, C.L. (2009). Echinodermata of the Gulf of Mexico. En: D.L. Felder, \& D.K. Camp (Eds.), Gulf of Mexico-Origins, Waters, and Biota. Biodiversity (pp. 1-1393), Texas A\&M University Press, College Station, Estados Unidos, Texas.

Pérez, L. (2005). Desarrollo embrionario y larval del pepino de mar Athyonidium chilensis (Semper, 1868) (Echinodermata: Holothuroidea). Tesis para optar al título de Biólogo Marino. Universidad Católica del Norte, pp. 35.

Perry, R.I., Walters, C., \& Boutillier, J. (1999). A framework for providing scientific advice for the management of new and developing invertebrate fisheries. Reviews in Fish Biology and Fisheries, 9, 125-150.

Platas-Rosado, D.E., \& Vilaboa-Arroniz, J. (2014). La acuacultura mexicana, potencialidad, retos y áreas de oportunidad. Revista Mexicana de Agronegocios, $35,1065-1071$

Piña-Espallargas, R. (2004). La pesquería de especies marinas con fines de ornato en México - El Parque Marino Loreto como estudio de caso (Tesis). Centro Interdisciplinario de Ciencias Marinas, Instituto Politécnico Nacional, La Paz, México.

Pitt, R., \& Nguyen, D.Q.D. (2004). Breeding and rearing of the sea cucumber Holothuria scabra in Viet Nam. En: A. Lovatelli, C. Conand, S. Purcell, S. Uthicke, J. Hamel, \& A. Mercier (Eds.), Advances in Sea Cucumber Aquaculture and Management FAO Fisheries Technical Paper. No. 436 (pp. 333-346), FAO, Rome.

Pomory C. (1989). Range extensions for Isostichopus badionotus Selenka, 1867 and Holothuria (Halodeima) grisea Selenka, 1867 (Echinodermata: Holothuroidea). Texas Journal of Science, 41, 330-331.

Purcell, S.W., Yves, S., \& Chantal, C. (2012). Commercially important sea cucumbers of the world. FAO Species Catalogue for Fishery Purposes. Rome: Food and Agriculture Organization, United Nations.

Purcell, J.E., Bexter, E.J., \& Fuentes, V.L. (2013). Advances in aquaculture hatchery technology, Woodhead Publishing limited.
Purcell, S.W., Polidoro, B.A., Hamel, J.-F., Gamboa, R.U., \& Mercier, A. (2014). The cost of being valuable: predictors of extinction risk in marine invertebrates exploited as luxury seafood. Proceedings of the Royal Society B, 281, 20133296.

Purcell, S.W., Conand, C., Uthicke, S., \& Byrne, M. (2016). Ecological roles of exploited sea cucumbers. Oceanography and Marine Biology: An Annual Review, 54, 367-386.

Purcell, S.W., Ngaluafe, P., Lalavanua, W., \& Ceccarelli, D.M. (2018). Market price trends of Latin American and Caribbean sea cucumbers inform fisheries management. Regional Studies in Marine Science, $17,127-132$.

Pyhälä, A., Fernández-Llamazares, A., Lehvävirta, H., Byg, A., Ruíz-Mallén, I., Salpeteur, M., \& Thornton, T.F. (2016). Global environmental change: local perceptions, understandings, and explanations. Ecology and Society, 21, 25.

Ramos-Miranda, J., Flores-Hernández, D., Flores-Ramos, E.F., Pech, D., Doto, J.L., Solís-Marín, F., AyalaPérez, L., del Rio Rodríguez, R., Rendón von Osten, J., Pacheco-Cervera, M., Can Nah, F., Duarte-Anchevida, A., \& Aguilar-Chávez, F. (2012). El pepino de mar (H. floridana) de las costas de Campeche, Informe Final. FOMIX-Campeche-CONACYT; Secretaria de Medio Ambiente y Aprovechamiento Sustentable (SMAAS); Gobierno del Estado de Campeche, Secretaría de Marina, Armada de México, Séptima Zona Naval, 88 pp.

Reyes, A., Carmona, A., Sepúlveda, A., Arias, E., Rojas, C., Barahona, N., Sasso, L., \& Lozada, E. (1991). Estado de situación y perspectivas de las pesquerías de recursos bentónicos, III, IV y V Región. Diagnóstico de las principales pesquerías bentónicas, Informe Técnico CORFO-IFOP. 85 pp.

Robledo, D., \& Freile-Pelegrín, Y. (2011). Managing the interactions between plants and animals in marine multi-trophic aquaculture: Integrated shrimp and valuable low food chain organisms with seaweeds. En: J. Seckbach \& Z. Dubinsky (Eds.), All flesh is grass, cellular origin, life in extreme habitats and astrobiology, 16, 365-381.

Rodríguez, J., Bayot, B., Amano, Y., Panchana, F., de Blas, I., Alday, V., \& Calderon, J. (2003). White spot syndrome virus infection in cultured Penaeus vannamei (Boone) in Ecuador with emphasis on histopathology and ultrastructure. Journal of Fish Disease, 26, 439-450.

Rodríguez-Serna, M., Carmona-Osalde, C., Guzmán-García, X., Puerto-Novelo, E. (2012). Primeras experiencias para el desarrollo del cultivo de holoturidos (Isostichopus badionotus y Holothuria floridana) endémicos del Golfo de México. Revista AquaTIC, 36, 3-10. 
Rogers, A. (2011). Recovery dynamics of the Caribbean longspined sea urchin, Diadema antillarum. A thesis submitted for the degree of Doctor of Philosophy Imperial College London, Department of Biology.

Rogers, A. (2018). Culture of the sea cucumbers Holothuria mexicana, Holothuria floridana and hybrids, and Isostichopus badionotus in former shrimp ponds: a Belize case study. Proceedings of the 71st Gulf and Caribbean Fisheries Institute, Nov. 5-9, 2018, San Andres, Colombia.

Rogers, A., Hamel, J.F., \& Mercier, A. (2018). Population structure and reproductive cycle of the commercial sea cucumber Holothuria mexicana (Echinodermata: Holothuroidea) in Belize. Revista de Biologia, 66, 1629-1648.

Rubilar, T., Barbieri, E.S., Gázquez, A., Avaro, M., VeraPiombo, M., Gittardi, A., Seiler, E.N., Fernández, J., Sepulvida, L., \& Chaar, F. (2020). In silico analysis of sea urchin pigments as potential therapeutic agents against SARS/CoV/2: main protease (Mpro) as a target. ChemRxiv.

Rueda, M., Rico-Mejía, F., \& Angulo-Vivero, W. (2011). Evaluación y manejo de la pesquería industrial de camarón de aguas someras en el Pacífico colombiano, En: J.M. Díaz, C. Vieira, \& G. Melo (Eds.), Diagnóstico de las principales pesquerías del Pacífico colombiano (pp. 93-108). Fundación Marviva - Colombia, Bogotá,

Sachs, J., \& Ladd, N. (2011). Climate and oceanography of the Galápagos in the 21st Century: expected changes and research needs. En: I. Larrea, \& G. Di Carlo (Eds.), Climate change vulnerability assessment of the Galápagos Islands. WWF and Conservation International, USA.

SAGARPA (2012). Plan de Manejo Pesquero de erizo rojo Strongylocentrotus franciscanus y erizo morado Strongylocentrotus purpuratus en la Península de Baja California, México, Diario Oficial, Primera Sección, Secretaría de Agricultura, Ganadería, Desarrollo Rural, Pesca y Alimentación, 20 de diciembre 2012, 31 pp.

Saito, M., Kunisaki, N., Urano, N., \& Kimura, S. (2002) Collagen as the major edible component of sea cucumber (Stichopus japonicus). Journal of Food Science, 67, 1319-1322.

Sarkis, S. (2015). Culture potential for the four-sided sea cucumber, Isostichopus badionotus, in Bermuda: An approach for conserving natural populations. Proceedings of the Gulf and Caribbean Fisheries Institute $68,475-477$.

Sarmiento-Rubiano, L.A. (2006). Alimentos funcionales, una nueva alternativa de alimentación. Revista Orinoquia, 10, 16-23.
SERNAP (2003). Anuario estadístico de pesca. Ministerio de Economía Fomento y Reconstrucción, 430 Chile, pp 1-156.

SERNAP (2008). Anuario estadístico de pesca. Ministerio de Economía Fomento y Reconstrucción, 433 Chile, pp. 1-156.

Silva, K. (2019). El cultivo del erizo rojo. Revista Mundo Acuícola No. 18 de abril, 2019. https://www.mundoacuicola.cl/new/revista/articulos/cultivo-de-erizo-rojo/

Sithisak, P., Pongtippatee, P., \& Withyachumnarnkul, B. (2013). Improving inland culture performance of juvenile sea cucumbers, Holothuria scabra, by coculture with red tilapia. Songklanakarin Journal of Science and Technology, 35, 501-505.

Slater, M. (2015). Use and exploitation of sea cucumbers. En: N. Brown, \& S. Eddy (Eds.), Echinoderm Aquaculture (pp. 57-73). John Wiley \& Sons, Inc.

Solís-Marín, F., Honey-Escandón, M.B., Herrero-Perezrul, M.D., Benítez-Villalobos, F., Díaz-Martínez, J.P., Buitrón-Sánchez, B.E., Palleiro-Nayar, J.S., \& Durán-González, A. (2013). The echinoderms of Mexico: Biodiversity, distribution and current stage of knowledge. En: J.J. Alvarado, \& F.A. SolísMarín (Eds.), Echinoderm Research and Diversity in Latin America (pp. 11-65). Springer-Verlag Berlin Heidelberg.

Sonnenholzner, J. (2017). Maricultura y piscicultura para el fomento acuícola en el Ecuador - pepino de mar Isostichopus fuscus. Reporte final interno del proyecto Subsecretaría de Acuicultura del Ecuador / ESPOLTECH / CENAIM-ESPOL, pp. 65.

Sonnenholzner, J., Searcy-Bernal, R., \& Panchana, M. (2017). The potential for propagation of the commercial sea cucumber Isostichopus fuscus (Ludwig, 1875 ) by induced transverse fission. Regional Studies in Marine Science, 9, 35-42.

Sonnenholzner, J., Alcívar, G., Márquez, A., \& Lodeiros, C. (2017). Los erizos Arbacia incisa y Eucidaris thouarsii (Echinodermata) como agentes de biocontrol del fouling en canastas de cultivo de Crassostrea gigas (Mollusca: Ostreidae). Revista de Biología Tropical, 65, S35-S41.

Sonnenholzner, J., Touron, N., Panchana-Orrala, M. (2018). Breeding, larval development, and growth of juveniles of the edible sea urchin Tripneustes depressus: A new target species for aquaculture in Ecuador. Aquaculture, 496, 134-145.

Sonnenholzner, J. (2019a). Desarrollo de protocolos de domesticación para el uso sostenible de nuevas especies marinas para consumo de alimentos y repoblación de bancos naturales - producción de semillas del pepino de mar Holothuria theeli (PIC-2014 CENAIM-002). Reporte final del proyecto. SENESCYT / ESPOL-TECH / CENAIM-ESPOL, pp. 61. 
Sonnenholzner, J. (2019b). Desarrollo de protocolos de domesticación para el uso sostenible de nuevas especies marinas para consumo de alimentos y repoblación de bancos naturales - producción de semillas del erizo de mar Tripneustes depressus (PIC-2014 CENAIM-002). Reporte final del proyecto. SENESCYT / ESPOL-TECH / CENAIM-ESPOL, pp. 59.

Sonnenholzner, J., Moreira, J., \& Panchana, M. (2019). Growth performance and survival of Holothuria theeli (holothurian) fed with feces of Tripneustes depressus (echinoid): a multi-trophic aquaculture approach. Aquaculture, 512, 34-45.

Stotz, W. (2000). When aquaculture restores and replaces an overfished stock: Is the conservation of the species assured? The case of the scallop Argopecten purpuratus in northern Chile. Aquaculture International, $8,237-247$

Sucklinga, C.C., Kelly, M.S., \& Symonds, R.C. (2020). Carotenoids in sea urchins En: J.M. Lawrence (Ed.). Sea urchins: Biology and ecology (pp. 209-217). Elsevier B.V

Sun, J., \& Chiang, F.-S. (2015). Use and exploitation of sea urchins. En: N. Brown, \& S. Eddy (Eds.), Echinoderm aquaculture (pp. 25-45). John Wiley \& Sons, Inc.

Tagliafico, A., Salomé-Rangel, M., Rago, N. (2011). Distribución y densidad de dos especies de holoturoideos en la isla de Cubagua, Venezuela. Revista de Biología Tropical, 59, 843-852.

Tegner, M.J., \& Dayton, P.K. (2000). Ecosystem effects of fishing in kelp forest communities. ICES Journal of Marine Science, 57, 579-589.

Thrush, S.F., Hewitt, J.E., Cummings, V.J., Dayton, P.K., Cryer, M., Turner, S.J., Funnell, G.A., Budd, R.G., Milburn, C.J., \& Wilkinson, M.R. (1998). Disturbance of the marine benthic habitat by commercial fishing: impacts at the scale of the fishery. Ecological Applications, 8, 866-879.

Tommasi, LR. (1969). Lista dos holothuroidea recentes do Brasil. Contribuições Avulsas do Instituto Oceanográfico. Universidade de São Paulo, série Oceanografia Biológica, São Paulo, 15, 1-29.

Toral-Granda, V. (2008). Population status, fisheries and trade of sea cucumbers in Latin America and the Caribbean. En: V. Toral-Granda, A. Lovatelli, \& M. Vasconcellos (Eds.), Sea cucumbers: A global review of fisheries and trade (pp. 213-229). FAO Fisheries and Aquaculture Technical Paper. No. 516. Rome, FAO.

Toral-Granda, V, Alvarado, J.J., Hamel, J.-F., Mercier, A., Benavides, M., \& Ortiz, P. (2013). Isostichopus badionotus. The IUCN Red List of Threatened
Species 2013. https://dx.doi.org/10.2305/IUCN. UK.2013-1.RLTS.T180519A1642750.en.

Troell, M., Naylor, R.L., Metian, M., Beveridge, M., Tyedmers, P.H., Folke, C., Arrow, K.J., Barrett, S., Crépin, A.S., Ehrlich, P.R., Gren, A., Kautsky, N., Levin, S.A., Nyborg, K., Österblom, H., Polasky, S., Scheffer, M., Walker, B.H., Xepapadeas, T., \& de Zeeuw, A. (2014). Does aquaculture add resilience to the global food system? Proceedings of the National Academy of Sciences, 111, 13257-13263.

Tuwo, A., \& Tresnati, J. (2015). Sea cucumber farming in Southeast Asia (Malaysia, Philippines, Indonesia, Vietnam). En: N. Brown, \& S. Eddy (Eds.), Echinoderm Aquaculture (pp. 331-352). John Wiley \& Sons, Inc.

UNESCO (2020). Statistics: Science technology and innovation 2020. http://uis.unesco.org

Uthicke, S. (2004). Overfishing of holothurians: Lessons from the Great Barrier Reef. En: A. Lovatelli, C. Conand, S. Purcell, S. Uthicke, J.-F. Hamel, \& A. Mercier (Eds.), Advances in sea cucumber Aquaculture and Management (pp. 163-171). FAO Fish. Tech. Paper, No. 463, FAO, Rome, Italy.

Van den Hoek, L.S., \& Bayoumi, E.K. (2017). Review Global Management utilization of sea cucumbers. IOSR Journal of Pharmacy and Biological Sciences, 12:1-7.

Vásquez, J. (2020). Loxechinus albus. En: J.M. Lawrence (Ed.). Sea urchins: Biology and ecology (pp. 431445). Elsevier B.V

Vásquez, J., \& Alonso-Vega, J.M. (2004). E1 Niño 1997-98 en el norte de Chile: efectos en la estructura y en la organización de comunidades submareales dominadas por algas pardas. En: S. Avaria, J. Carrasco, J. Rutllant, \& E. Yañez (Eds.), El Niño-La Niña $1997-$ 2000. Sus efectos en Chile (pp.119-135). CONA, Chile, Valparaíso.

Vázquez-Sauceda, M., Sánchez-Martínez, J.G., Pérez-Castañeda, R., Rábago-Castro, J.L., Aguirre-Guzmán, G., \& Vargas-Cruz, D.Y. (2016). White Spot Syndrome Virus (WSSV) and Necrotizing Hepatopancreatitis (NHP) detection in wild shrimp of the San Andrés Lagoon, Mexico. Revista de Biología Marina y Oceanografia, 51, 455-459.

Vega, J.M.A., Vásquez, J.A., \& Buschmann, A.H. (2005). Population biology of the subtidal kelps Macrocystis integrifolia and Lessonia trabeculata (Laminariales, Phaeophyceae) in an upwelling ecosystem of northern Chile: interannual variability and El Nino 1997-1998, Revista Chilena de Historia Natural, $78,33-50$.

Vela-Gallo, C.I. (2017). Desarrollo embrionario y larval del pepino de mar Parastichopus parvimensis en Isla 
Natividad, BCS - México. Tesis de Biólogo Marino, Universidad Autónoma de Baja California Sur, México. Pp. 67.

Watson, R, \& Pauly, D. (2001). Systematic distortion in world fisheries catch trends. Nature, 424, 534-536.

Wurmann, C. (2019). Aquaculture in Latin America and the Caribbean: Progresses, opportunities and challenges. Aquatechnica, 1, 1-21.

Yu, Z., Hu, C., Zhou, Y., Li, H., \& Peng, P. (2012). Survival and growth of the sea cucumber Holothuria leucospilota Brandt: A comparison between suspended and bottom cultures in a subtropical fish farm during summer. Aquaculture Research, 44, 114-124.
Zacarías-Soto, M., Olvera-Novoa, M.A., PensamientoVillarauz, S., \& Sánchez-Tapia, I. (2013). Spawning and larval development of the four-sided sea cucumber, Isostichopus badionotus (Selenka 1867), under Controlled Conditions. Journal of the World Aquaculture Society, 44, 694-705.

Zamora, S., \& Stotz, W. (1994). Cultivo masivo en Laboratorio de juveniles de erizo Loxechinus albus (Molina, 1782) (Echinodermata: Echinoidea). Investigación Pesquera, 38: 37-54.

Zhou, Y., Yang, H., Liu, S., Yuan, X., Mao, Y., Liu, Y., $\mathrm{Xu}, \mathrm{X} .$, \& Zhang, F. (2006). Feeding and growth on bivalve biodeposits by the deposit feeder Stichopus japonicus Selenka (Echinodermata: Holothuroidea) co-cultured in lantern nets. Aquaculture, 256, 510-520. 